Article

\title{
Numerical Investigation on Forced Hybrid Nanofluid Flow and Heat Transfer Inside a Three-Dimensional Annulus Equipped with Hot and Cold Rods: Using Symmetry Simulation
}

\author{
Aysan Shahsavar Goldanlou 1,2, Mohammad Badri ${ }^{3}$, Behzad Heidarshenas 4 (D), \\ Ahmed Kadhim Hussein ${ }^{5}$, , Sara Rostami ${ }^{6,7}$ (D) and Mostafa Safdari Shadloo ${ }^{8, *(D)}$ \\ 1 Institute of Research and Development, Duy Tan University, Da Nang 550000, Vietnam; \\ aysanshahsavargoldanlou@duytan.edu.vn \\ 2 Faculty of Electrical-Electronic Engineering, Duy Tan University, Da Nang 550000, Vietnam \\ 3 Department of Mechanical Engineering, University of Kashan, Kashan 8731753153, Iran; \\ badri_m@grad.kashanu.ac.ir \\ 4 College of Mechanical of Electrical Engineering, Nanjing University of Aeronautics and Astronautics, \\ Nanjing 210016, China; behzadheidarshenas@nuaa.edu.cn \\ 5 College of Engineering-Mechanical Engineering Department, University of Babylon, Babylon 51001, Iraq; \\ ahmed.hussein.eng@uobabylon.edu.iq \\ 6 Laboratory of Magnetism and Magnetic Materials, Advanced Institute of Materials Science, \\ Ton Duc Thang University, Ho Chi Minh City 758307, Vietnam; sara.rostami@tdtu.edu.vn \\ 7 Faculty of Applied Sciences, Ton Duc Thang University, Ho Chi Minh City 758307, Vietnam \\ 8 CORIA-UMR 6614, CNRS \& INSA of Rouen, Normandie University, 76000 Rouen, France \\ * Correspondence: msshadloo@coria.fr
}

Received: 17 July 2020; Accepted: 22 October 2020; Published: 14 November 2020

\begin{abstract}
A 3D computational fluid dynamics method is used in the current study to investigate the hybrid nanofluid (HNF) flow and heat transfer in an annulus with hot and cold rods. The chief goal of the current study is to examine the influences of dissimilar Reynolds numbers, emissivity coefficients, and dissimilar volume fractions of nanoparticles on hydraulic and thermal characteristics of the studied annulus. In this way, the geometry is modeled using a symmetry scheme. The heat transfer fluid is a water, ethylene-glycol, or water/ethylene-glycol mixture-based $\mathrm{Cu}-\mathrm{Al}_{2} \mathrm{O}_{3} \mathrm{HNF}$, which is a Newtonian NF. According to the findings for the model at $\mathrm{Re}=3000$ and $\phi_{1}=0.05$, all studied cases with different base fluids have similar behavior. $\phi_{1}$ and $\phi_{2}$ are the volume concentration of $\mathrm{Al}_{2} \mathrm{O}_{3}$ and $\mathrm{Cu}$ nanoparticles, respectively. For all studied cases, the total average Nusselt number $\left(\mathrm{Nu} u_{\text {ave }}\right)$ reduces firstly by an increment of the volume concentrations of $\mathrm{Cu}$ nanoparticles until $\phi_{2}=0.01$ or 0.02 and then, the total $N u_{\text {ave }}$ rises by an increment of the volume concentrations of $\mathrm{Cu}$ nanoparticles. Additionally, for the case with water as the base fluid, the total $N u_{\text {ave }}$ at $\phi_{2}=0.05$ is higher than the values at $\phi_{2}=0.00$. On the other hand, for the other cases, the total $N u_{\text {ave }}$ at $\phi_{2}=0.05$ is lower than the values at $\phi_{2}=0.00$. For all studied cases, the case with water as the base fluid has the maximum $N u_{\text {ave }}$. Plus, for the model at $\operatorname{Re}=4000$ and $\phi_{1}=0.05$, all studied cases with different base fluids have similar behavior. For all studied cases, the total $N u_{\text {ave }}$ reduces firstly by an increment of the volume concentrations of $\mathrm{Cu}$ nanoparticles until $\phi_{2}=0.01$ and then, the total $N u_{\text {ave }}$ rises by an increment of the volume concentrations of $\mathrm{Cu}$ nanoparticles. The $N u_{\text {ave }}$ augments are found by an increment of Reynolds numbers. Higher emissivity values should lead to higher radiation heat transfer, but the portion of radiative heat transfer in the studied annulus is low and therefore, has no observable increment in HNF flow and heat transfer.
\end{abstract}

Keywords: steady-state solution; forced convection; hybrid nanofluid; Nusselt number; streamlines 


\section{Introduction}

Heat exchangers are types of equipment that have many industrial applications and this factor makes their performance improvement an attractive subject for researchers. Extensive research in this field has led to the development of new methods to improve the performance of heat exchangers, some of the most important of which are the use of corrugated surfaces [1-3], turbulators [4-6], fins [7-9], magnetic fields [10-12], and the replacement of common coolants with nanofluids (NFs) [13-15]. The suspension of nanoparticles in conventional coolants improves their cooling performance, and this fact has been confirmed in many laboratory-based and numerical studies [16-18].

All of the above methods, in turn, improve the performance of heat exchangers, but researchers are always looking for ideas to improve the effectiveness of these methods. A group of researchers posed the question: if adding one nanoparticle to a coolant improves its cooling performance, does adding two types of nanoparticles to the coolants not lead to a further improvement in cooling performance? Numerous experimental [19-21] and numerical [22-24] studies were conducted to answer this question, and it was finally found that the cooling performance of hybrid nanofluids (HNFs) was generally better than that of conventional NFs. Li et al. [25] investigated numerically different features of convection heat transfer inside a cavity equipped with a twin-web turbine disk and pin fins. Their obtained results indicate that there is a clockwise circular fluid flow inside the studied cavity which influences the front and back web for the improvement of the local convection heat transfer coefficients. The back web, $N u$, is strangely higher than the $N u$ of the front web, and the back web temperature is perceptibly lower than the front web temperature. Chorin et al. [26] studied experimentally free convective heat transfer in a differentially heated cavity equipped with localized turbulators. The turbulator was located in the warm boundary coating of the cavity fluid flow. Experiments were carried out in heat transfers, temperature profiles, and velocity fields terms. The effect of the vertical location and the length for a conducting turbulator and an insulator was investigated. For the insulator turbulator, a fluid flow part diverged inside the colder turbulator region, leading to a downstream heat transfer upsurge. Giwa et al. [27] investigated experimentally and numerically different uniform magnetic induction effects on heat transfer presentation of a rectangular cavity equipped with aqueous HNF. The aqueous HNF's thermal properties had been studied for different nanoparticle volume fractions and various temperature ranges. Their obtained results show that by employing the vertically magnetic field on the cavity-side walls, the maximum $N u$ improvement was attained in compression with the model which did not have a magnetic field. Furthermore, it was realized that an increment in the magnetic field can improve the heat transfer characteristics significantly. Mansouri et al. [28] considered numerically conjugate conduction-convection heat transfer in a cavity filled with air and equipped with a rhombus conducting block exposed to subdivision, such as opposing and cooperating roles. The temperature and flow results were obtained by employing the Lattice Boltzmann technique with the finite volume method and the multi-relaxation time collision scheme. The influences of the initial solid block thermal conductivity on heat transfer and fluid flow inside the cavity were studied. Their obtained results present that the initial block subdivision leads to a reduction in heat transfer inside the cavity. Thiers et al. [29] studied numerical heat transfer improvement inside a rectangular differentially heated cavity with different thermal perturbations on cold and hot walls. The different effects of wave characteristics such as phase shift, frequency, and amplitude, and also the disturbance area's vertical location, were studied in the range of different Rayleigh numbers. The key aim of their study was to find the optimum location of differentially heated sources for heat transfer improvement. Ataei-Dadavi et al. [30] considered experimental fluid flow and heat transfer characteristics in a differential side-heated coarse porous media cavity. Their findings illustrated that the presence of a porous medium in the cavity leads to heat transfer reduction compared to the cavity without porous media. They attained a novel correlation method to predict the $N u$ for coarse porous media-based cavities. Farsani et al. [31] investigated heat transfer improvement in cavities using baffles melting, which were filled with gallium. They modeled the process of the phase using the fixed grid-based enthalpy-porosity technique coupled with the Semi-Implicit Method for 
Pressure Linked Equations (SIMPLE) algorithm. They reported the streamlines and isotherm lines, and also, $\mathrm{Nu}$ values, on hot walls to investigate and analyze the problem. Vishnu et al. [32] examined numerically different conditions of heat transfer inside an oblique cavity located in supersonic flow. They simulated a 2D compressible unsteady turbulent flow field using the finite volume method and the Harten-Lax-van Leer-Contact (HLLC) scheme. They also validated their numerical procedure with available empirical and mathematical data. Sadaghiani et al. [33] examined parametrically and experimentally different influences of bubble coalescence on critical heat flux and pool boiling heat transfer in a cavity. They examined different surface wettability effects on the structured surfaces' performance by employing a Teflon film with a thickness of $50 \mathrm{~nm}$. Additionally, they examined bubble dynamics by employment of a high-speed camera. Pan et al. [34] experimentally considered the heat transfer features of a heat exchanger equipped with microchannel and fan-shaped cavities. Their obtained data illustrated that the microchannel heat exchanger's performance, which is equipped with fan-shaped cavities, is sharply better than the heat exchangers without fan-shaped cavities and also, their pressure drop is lower than the heat exchangers without fan-shaped cavities. Balotaki et al. [35] modeled numerically, and by employing the lattice Boltzmann method, the heat transfer of free natural convections in a triangular cavity filling with different operating fluids, including water, $\mathrm{TiO}_{2}-\mathrm{H}_{2} \mathrm{O}$, $\mathrm{Al}-\mathrm{H}_{2} \mathrm{O}$, and $\mathrm{Cu}-\mathrm{H}_{2} \mathrm{O}$, and equipped with double distribution functions. They reported various interesting results such as average predicted $\mathrm{Nu}$, heat lines, an isothermal line, streamlines, and entropy generation values. Liu and Huang [36] studied numerically different effects using different linear thermal forcing models on fluid flow and convective heat transfer in a rectangular finned enclosure. The results showed fluctuations in the flow above the fin. Seo et al. [37] numerically analyzed the performance of a naturally cooled rectangular enclosure with a sinusoidal cylinder. The outcomes revealed the significant impact of cylinder diameter and Rayleigh number on the performance features of the enclosure. Razzaghpanah and Sarunac [38] simulated the free convection from a bundle of heated cylinders submerged in molten salt. They proposed a correlation set for Nusselt number in terms of Rayleigh number. Krakov and Nikiforov [39] employed numerical data to reveal the impact of interior cylinder shape on thermomagnetic convection heat transfer through a horizontal annulus. It was demonstrated that the shape of the interior cylinder can increase the heat transfer by $40-50 \%$. Pawar et al. [40] numerically investigated convection heat transfer and forced laminar steady state flow inside a cylindrical finned cavity at various incidence angles. Due to analyzing aerodynamic characteristics, factors such as local time-averaged flux and vorticity, length of recirculation, Strouhal number and moment, and lift and drag coefficients were reported by them. Alam et al. [41] considered the flow around a cylinder with variable cross-sections and analyzed the dependence of velocity and temperature field on corner radius and attack angle. The dramatic role of boundary layers in improving heat transfer was reported. The main reason for this behavior is that the primary wake bubbles are mostly linked to the forces. Vyas et al. [42] conducted an experimental numerical assessment on fluid flow in the wake region of a cylinder submerged in a conduit, considering the impacts of blockage ratio. It was realized that the highest downstream distance traveled by the vortices was at a blockage ratio of 0.38. Hadžiabdić et al. [43] simulated the flow and heat transfer around a rotating cylinder. They reported the high local rates of heat transfer in the cylinder. Furthermore, they found that the overall mean predicted $N u$ values of rotational cylinder did not have a significant variation inside the cylinder but its time-average presented some changes in comparison with the basic cylinder.

The literature review clarifies that even though the influence of using NF for electrical heat exchangers was evaluated, to the best knowledge of the authors, there is not any research which examines the symmetry simulation of forced HNF flow and heat transfer in a three-dimensional annulus equipped with hot and cold rods. The chief goal of the current study is to examine the influences of dissimilar Reynolds numbers, emissivity coefficients, and dissimilar volume fractions of nanoparticles on hydraulic and thermal characteristics of the studied annulus. Moreover, in this study, the geometry is modeled using symmetry scheme. 


\section{Methodology}

\subsection{Problem Statement and Governing Equations}

Figure 1 demonstrates a basic and simulated three-dimensional cylindrical shape cavity (annulus) equipped with hot and cold rods in the present study. In the present paper, this geometry is analyzed using a symmetry boundary condition. Figure 1 shows, on the right side, a schematic diagram of the studied configuration. The height of the cylinder is changed from $300 \mathrm{~mm}$. Additionally, the height of the square is changed from 46.03 to $70.71 \mathrm{~mm}$, the length of the square is $1000 \mathrm{~mm}$, and the gravity influences are determined in $z$ direction. This is a hypothetical geometry and was designed by the authors of the article. However, it has many applications in electrical components and electronics industries. The system is made of an insulator in the center and outer sides of the cylinder, with a boundary condition of zero heat flux. However, this material is presumed with two dissimilar emissivity values of 0.2 and 0.5 for analyzing its influences on radiation heat transfer. Moreover, two dissimilar Reynolds numbers, $\operatorname{Re}=3000$ and 4000, are in transient regime. The initial $\mathrm{NF}$ temperature is $T_{\text {initial }}=350 \mathrm{~K}$ and the cold side temperature is $T_{c}=300 \mathrm{~K}$. The hot side temperature can be $T_{h}=430 \mathrm{~K}$. The heat transfer fluid is a water-, ethylene-glycol-, or water/ethylene-glycol mixture-based $\mathrm{Cu}-\mathrm{Al}_{2} \mathrm{O}_{3} \mathrm{HNF}$, which creates a Newtonian NF. To attain the most proficient Newtonian $\mathrm{NF}$ in the current research, $\mathrm{Cu}$ and $\mathrm{Al}_{2} \mathrm{O}_{3}$ nanoparticles were added to the base fluid in different volume concentrations of 0.01 to 0.05 with diameters of $24 \mathrm{~nm}$. Table 1 presents the thermophysical features of the base fluid and nanoparticles.

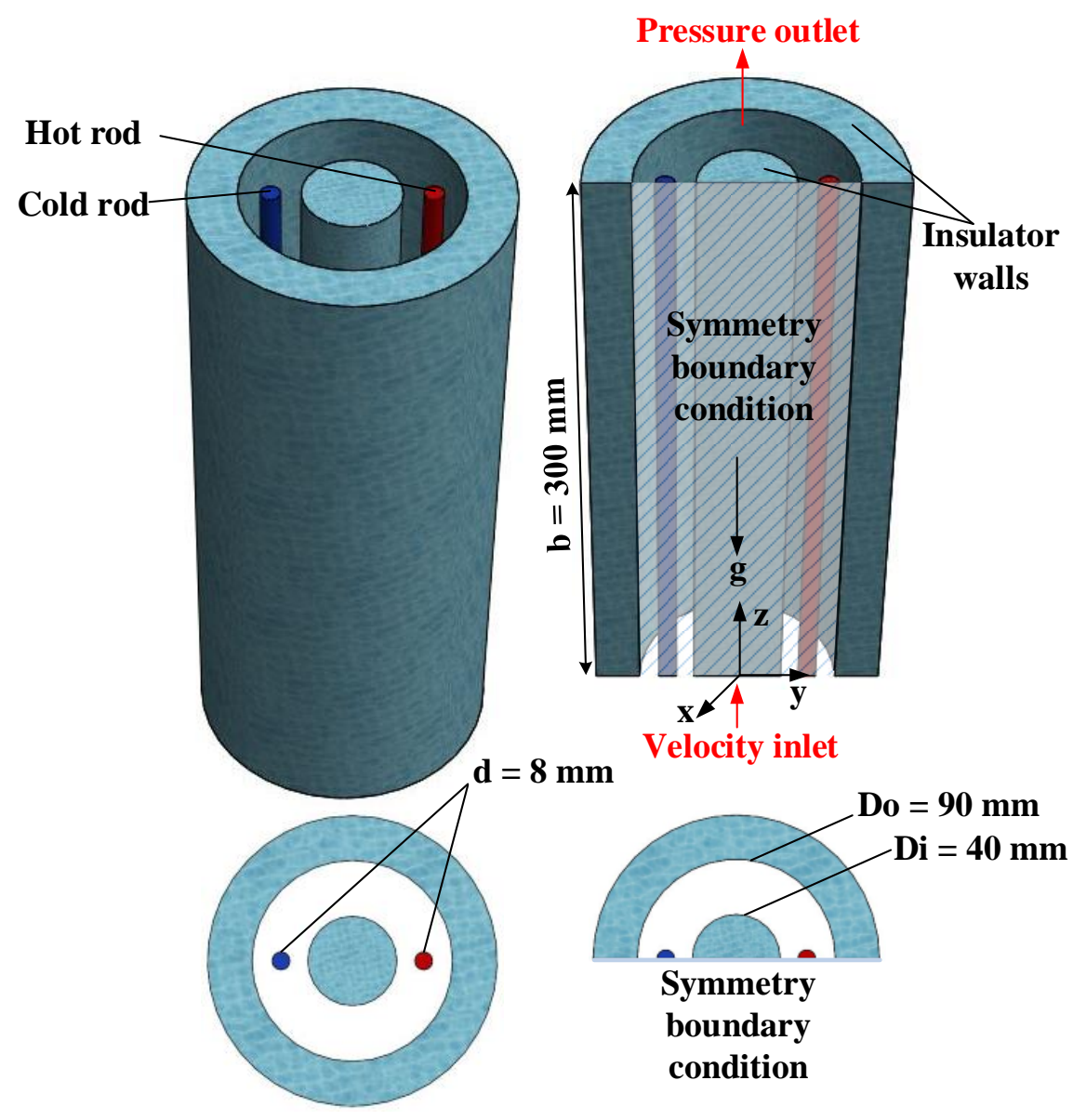

Figure 1. Schematic diagrams of the basic (left) and computation domain (right) geometries in the present paper. 
Table 1. Base fluid and nanoparticle numerical values for thermophysical properties ( $\mathrm{T}=298 \mathrm{~K})$ [44].

\begin{tabular}{|c|c|c|c|}
\hline Thermophysical Properties & $k(\mathrm{~W} / \mathrm{m} \cdot \mathrm{K})$ & $c_{p}(\mathrm{~J} / \mathrm{kg} \cdot \mathrm{K})$ & $\rho\left(\mathrm{kg} / \mathrm{m}^{3}\right)$ \\
\hline $\mathrm{Cu}$ & 400 & 385 & 8933 \\
\hline $\mathrm{Al}_{2} \mathrm{O}_{3}$ & 40 & 765 & 3970 \\
\hline Ethylene-glycol & 0.252 & 2415 & 1114.4 \\
\hline $\mathrm{H}_{2} \mathrm{O}$ & 0.613 & 4179 & 997.1 \\
\hline $\mathrm{H}_{2} \mathrm{O} /$ ethylene-glycol mixture & 0.3799 & 3300 & 1067.5 \\
\hline
\end{tabular}

The equations presented in Table 2 have been used to calculate the thermophysical properties of NF. The density $\left(\rho_{h n f}\right)$ and specific heat $\left(c_{P, h n f}\right)$ of the HNF at each section temperature $\left(T_{m}\right)$ were calculated using the equations presented in Table 2 [44], where $\phi_{1}$ is the volume concentration of $\mathrm{Al}_{2} \mathrm{O}_{3}$ and $\phi_{2}$ is the volume concentration of $\mathrm{Cu}$ nanoparticles. Moreover, the effective dynamic viscosity and thermal conductivity of HNF were obtained by the equations in Table 2.

Table 2. Useful equations to model the studied nanofluid (NF) in the present work [44].

\begin{tabular}{ll}
\hline Density & $\rho_{h n f}=\left(1-\phi_{2}\right)\left[\left(1-\phi_{1}\right) \rho_{b f}+\phi_{1} \rho_{n p, 1}\right]+\phi_{2} \rho_{n p, 2}$ \\
Specific heat & $\left(\rho c_{p}\right)_{h n f}=\left(1-\phi_{2}\right)\left[\left(1-\phi_{1}\right)\left(\rho c_{p}\right)_{b f}+\phi_{1}\left(\rho c_{p}\right)_{n p, 1}\right]+\phi_{2}\left(\rho c_{p}\right)_{n p, 2}$ \\
Thermal conductivity & $k_{h n f}=k_{n f}\left[k_{n p, 2}+2 k_{n f}-2 \phi_{2} \frac{k_{n f}-k_{n p, 2}}{k_{n p, 2}}+2 k_{n f}+\phi_{2}\left(k_{n f}-k_{n p, 2}\right)\right]$ \\
& $k_{n f}=k_{b f}\left[k_{n p, 1}+2 k_{b f}-\frac{2 \phi_{1}\left(k_{b f}-k_{n p, 1}\right)}{k_{n p, 1}}+2 k_{b f}+\phi_{1}\left(k_{b f}-k_{n p, 1}\right)\right]$ \\
Dynamic viscosity & $\mu_{h n f}=\frac{\mu_{b f}}{\left(1-\phi_{1}\right)^{2.5}\left(1-\phi_{2}\right)^{2.5}}$ \\
\hline
\end{tabular}

A 3D numerical analysis has been used in the current research to examine the transient HNF flow and heat transfer in an annulus with hot and cold rods. Given that the Reynolds number is more than 2300, the flow regime is considered transient. The Reynolds-averaged Navier-Stokes (RANS) equations with the shear-stress (SST) $k-\omega$ turbulence model were used for simulating the turbulence regime. The used equations can be defined as reported in Table 3. As mentioned earlier, in the current modeling, the SST $k-\omega$ turbulence model [45] has been presumed as the turbulence model [46-53]. This is used to have a better forecast of the flow conditions, such as large normal strain, strong acceleration, reverse pressure gradients, and separating flow, which can occur in the HNF flow appearances adjacent to the rods and walls. Based on the SST $k-\omega$ model, the turbulence kinetic energy (k) and specific dissipation rate $(\omega)$ can be attained by the equations reported in Table 3 , where $\Omega_{i j}$ is the mean rate-of-rotation tensor and $F_{1}$ and $F_{2}$ are the blending functions. Additionally, $D_{\omega}^{+}$is the positive portion of the cross-diffusion term. The constant values reported in Table 3 are defined in Table 4. All equations were resolved until the maximum residual of grid control volume became smaller than $10^{-7}$.

The Monte Carlo method has been used for modeling the radiation in the annulus gap. In this model, the radiation has been determined to affect the domain by heating its surface, without radiant energy transfer directly to the domain (Surface-to-Surface transfer mode (S2S)). The spectral dependency of the radiative heat transfer equation was estimated using the Gray Model (GM), which determines whether all radiation amounts are closely uniform through the spectrum. The inner rod and outer wall are determined as insulators and no heat transfer occurs in these sections.

It was also predictable that the radiation mechanism could not play a decisive role in heat transfer. However, the goal was to model the problem with the least assumptions and the most accurate details. Therefore, despite the low share of radiation in heat transfer, its effect was considered.

In order to simulate the nanofluid flow inside the cylinder, the single-phase technique was employed. Just the thermophysical characteristics were calculated at different temperatures and nanoparticle volume fractions and have been entered into software. 
Table 3. Governing equations and parameters of interest [45].

\begin{tabular}{|c|c|}
\hline Continuity equation & $\frac{\partial}{\partial x_{i}}\left(\rho u_{i}\right)=0$ \\
\hline \multirow{3}{*}{ Momentum equation } & $\frac{\partial}{\partial x_{i}}\left(\rho u_{i} u_{j}\right)=-\frac{\partial p}{\partial x_{i}}+\frac{\partial \tau_{i j}}{\partial x_{j}}+\rho g_{i}$ \\
\hline & $\tau_{i j}=\frac{\mu^{*} \partial u_{i}}{\partial x_{j}}$ \\
\hline & $\mu^{*}=\mu+\mu_{t}$ \\
\hline \multirow{3}{*}{ Energy equation } & $\frac{\partial}{\partial x_{i}}\left(\rho c_{p} u_{i} T\right)=\frac{\partial}{\partial x_{i}}\left(\frac{\lambda^{*} \partial T}{\partial x_{i}}\right)+Q i$ \\
\hline & $\lambda^{*}=\lambda+\lambda_{t}$ \\
\hline & $\lambda_{t}=\frac{c_{p} \mu_{t}}{\sigma_{t}}$ \\
\hline \multirow{17}{*}{ Turbulence equations } & $\frac{\partial}{\partial x_{i}}\left(\rho u_{i} k\right)=\frac{\partial}{\partial x_{i}}\left[\left(\mu+\frac{\mu_{t}}{\sigma_{k}}\right) \frac{\partial k}{\partial x_{i}}\right]+G_{k}-Y_{k}$ \\
\hline & $\frac{\partial}{\partial x_{i}}\left(\rho u_{i} \omega\right)=\frac{\partial}{\partial x_{i}}\left[\left(\mu+\frac{\mu_{t}}{\sigma_{\omega}}\right) \frac{\partial k}{\partial x_{i}}\right]+G_{\omega}-Y_{\omega}+D_{\omega}$ \\
\hline & $\mu_{t}=\frac{\rho k}{\omega} \frac{1}{\max \left\{\frac{1}{a^{*}}, \frac{\Omega F_{2}}{a_{1} \omega}\right\}}$ \\
\hline & $\Omega=\sqrt{2 \Omega_{i j} \Omega_{i j}}$ \\
\hline & $\Omega_{i j}=\frac{1}{2}\left(\frac{\partial u_{i}}{\partial x_{j}}-\frac{\partial u_{j}}{\partial x_{i}}\right)$ \\
\hline & $\sigma_{k}=\frac{1}{\frac{F_{1}}{\sigma_{k, 1}}+\frac{1-F_{1}}{\sigma_{k, 2}}}$ \\
\hline & $\sigma_{\omega}=\frac{1}{\frac{F_{1}}{\sigma_{\omega, 1}}+\frac{1-F_{1}}{\sigma_{\omega, 2}}}$ \\
\hline & $F_{1}=\tanh \left(\Phi_{1}^{4}\right)$ \\
\hline & $F_{2}=\tanh \left(\Phi_{2}^{2}\right)$ \\
\hline & $\Phi_{1}=\min \left\{\max \left\{\frac{\sqrt{k}}{0.09 \omega y}, \frac{500 \mu}{\rho y^{2} \omega}\right\}, \frac{4 \rho k}{\sigma_{\omega, 2} D_{\omega}^{+} y^{2}}\right\}$ \\
\hline & $\Phi_{2}=\max \left\{\frac{2 \sqrt{k}}{0.09 \omega y}, \frac{500 \mu}{\rho y^{2} \omega}\right\}$ \\
\hline & $D_{\omega}^{+}=\max \left\{\frac{2 \rho}{\omega \rho_{\omega, 2}} \frac{\partial k}{\partial x_{i}} \frac{\partial \omega}{\partial x_{i}}, 10^{-20}\right\}$ \\
\hline & $\alpha^{*}=\alpha_{\infty}^{*}\left(\frac{\alpha_{0}^{*}+\frac{\mathrm{Re}_{t}}{R_{k}}}{1+\frac{\mathrm{Re}_{t}}{R_{k}}}\right), \quad \alpha_{0}^{*}=\frac{\beta_{i}}{3}, \quad \operatorname{Re}_{t}=\frac{\rho k}{\mu \omega}, \quad \beta_{i}=F_{1} \beta_{i, 1}+\left(1-F_{1}\right) \beta_{i, 2}$ \\
\hline & $G_{k}=\tau_{t, i j} \frac{\partial u_{i}}{\partial x_{j}}, \tau_{t, i j}=\mu_{t}\left(\frac{\partial u_{i}}{\partial x_{j}}+\frac{\partial u_{j}}{\partial x_{i}}\right)-\frac{2}{3} \rho k \delta_{i j}$ \\
\hline & $Y_{k}=\rho \beta^{*} k \omega, G_{\omega}=\frac{\rho \alpha}{\mu_{t}} G_{k}, Y_{\infty}=\rho \beta_{i} \omega^{2}$ \\
\hline & $\alpha=\frac{\alpha_{\infty}}{\alpha^{*}}=\left(\frac{\alpha_{0}^{*}+\frac{\mathrm{Re}_{t}}{R_{k}}}{1+\frac{\mathrm{Re} t}{R_{k}}}\right), \alpha_{\infty}=F_{1} \alpha_{\infty, 1}+\left(1-F_{1}\right) \alpha_{\infty, 2}$ \\
\hline & $\alpha_{\infty, 1}=\frac{\beta_{i, 1}}{\beta_{\infty}^{*}}-\frac{\kappa^{2}}{\sigma_{\omega, 1} \sqrt{\beta_{\infty}^{*}}}, \alpha_{\infty, 2}=\frac{\beta_{i, 2}}{\beta_{\infty}^{*}}-\frac{\kappa^{2}}{\sigma_{\omega, 2} \sqrt{\beta_{\infty}^{*}}}$ \\
\hline Parameters of interest & $\alpha_{n f}=\frac{k_{n f}}{\left(\rho c_{p}\right)_{n f}}, \operatorname{Re}=\frac{U_{r e f} D_{h}}{v_{f}}, \mathrm{Nu}=\frac{k_{n f}}{k_{f}} \int \frac{\partial T}{\partial x}$ \\
\hline
\end{tabular}

Table 4. Constant values of the shear-stress (SST) $k-\omega$ turbulence model [45].

\begin{tabular}{ccccccccccc}
\hline$\sigma_{t}$ & $\alpha_{k, 1}$ & $\alpha_{k, 2}$ & $\alpha_{\omega, 1}$ & $\alpha_{\omega, 2}$ & $\boldsymbol{a}_{1}$ & $\boldsymbol{\beta}_{i, 1}$ & $\boldsymbol{\beta}_{i, 2}$ & $\boldsymbol{\beta}_{\infty}^{*}$ & $\boldsymbol{\kappa}$ & $\boldsymbol{R}_{\boldsymbol{k}}$ \\
\hline 0.85 & 1.176 & 1.000 & 2.000 & 1.168 & 0.31 & 0.0750 & 0.0828 & 0.0900 & 0.41 & 6 \\
\hline
\end{tabular}

\subsection{Validation}

As displayed in Figure 2, a grid independency study was implemented for the studied cavity containing $\mathrm{Al}_{2} \mathrm{O}_{3}-\mathrm{Cu}$ /water $\mathrm{HNF}$ to examine the influences of mesh sizes on the findings. For the 
validation, the emissivity of the cylinder is constant and equal to 0.2 . Additionally, the volume fraction of the $\mathrm{Al}_{2} \mathrm{O}_{3}$ nanoparticles is 0.05 . A non-uniform structured mesh was used for the channel. Moreover, the near-wall mesh was fine enough to be able to resolve the viscous sublayer $(y+\leq 1)$. As observed, several meshes have been tested versus different Reynolds numbers and volume concentrations of Cu nanoparticles. Finally, it was determined that the mesh configurations, including 113,285 nodes, had acceptable precision with a maximum error of $3 \%$.

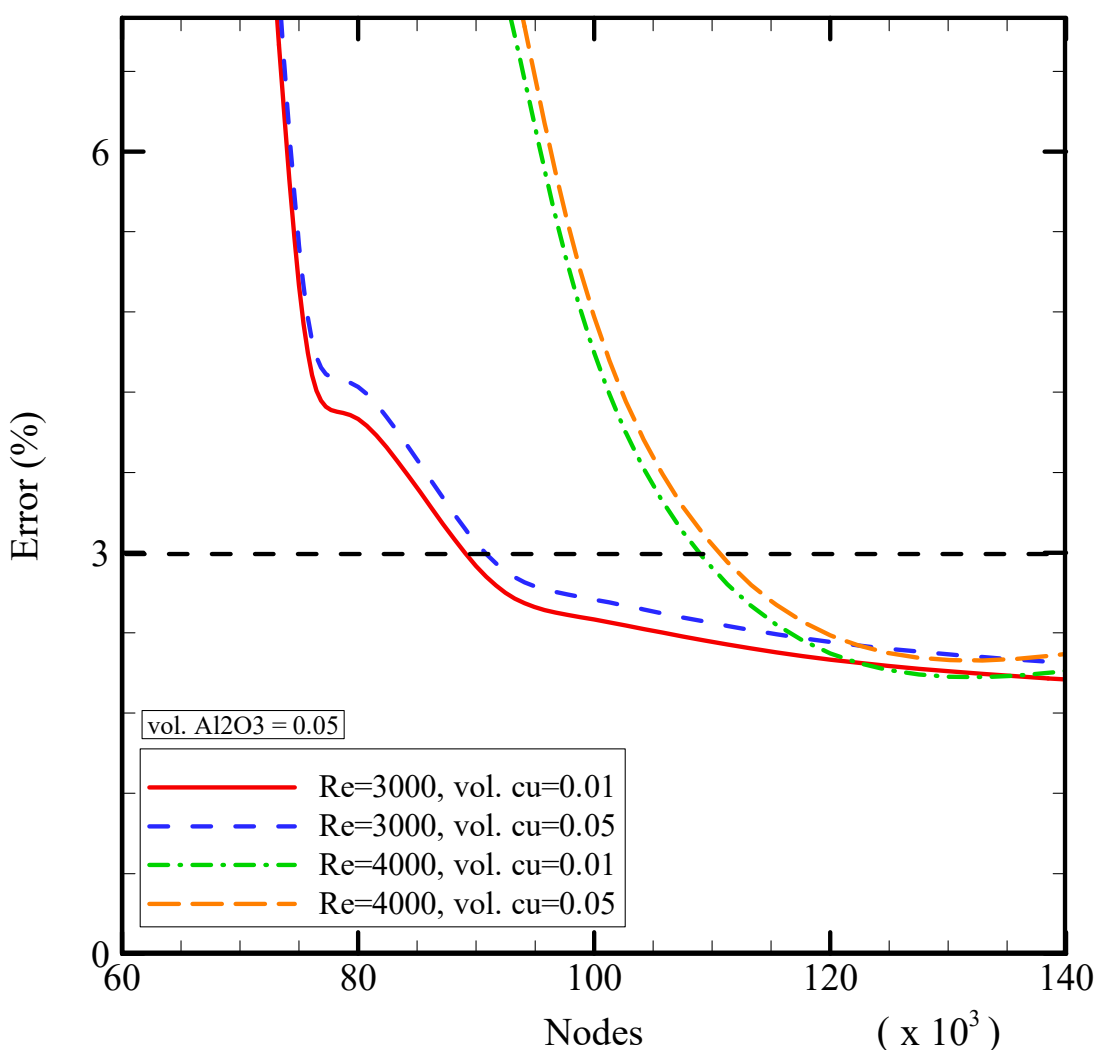

Figure 2. Mesh independency test.

Figure 3 shows code validation in the present study. Figure 3 a illustrates dimensionless temperature dissimilarity versus dimensionless distance to validate the obtained results in the present work and the empirical data of Kuehn and Goldstein [54]. Due the lack of empirical results for natural heat transfer in a cylinder, the numerical process has been validated with the presented empirical data of Kuehn and Goldstein [54] for $\Delta T=0.371 \mathrm{~K}, \operatorname{Pr}=5.45, \mathrm{Ra}_{L}=2.09 \times 10^{5}, L / 2 \mathrm{ri}=0.8$, and $T_{a v g}=303.18 \mathrm{~K}$, providing $T_{i}>T_{0}$. The judgments for different temperature profiles at various angles are indicated in Figure 3. It is seen clearly that there is a remarkable coincidence between the obtained results from reference [54] and the numerical data in the present investigation.

In addition, Figure $3 b$ illustrates Nusselt number variation versus Reynolds number $(2500<\operatorname{Re}<3900)$ to validate the obtained results in the present work and the numerical data of Liu and Yu [55] in the transient flow regime. It is seen clearly that there is a good agreement between the obtained results from reference [55] and the numerical data in the present investigation.

Due to the specific geometric conditions of the problem, the boundary conditions, and the explanations in the manual of ANSYS-Fluent software, using the symmetry boundary condition in the present work is a very effective and appropriate method for modeling. In order to validate the boundary condition, Figure $3 \mathrm{c}$ is plotted. In this diagram, the results of modeling a full cylinder and a half cylinder modeled with the symmetry condition are presented. The good agreement of the answers is well observed, which indicates the correctness of the boundary conditions used. 
(a)

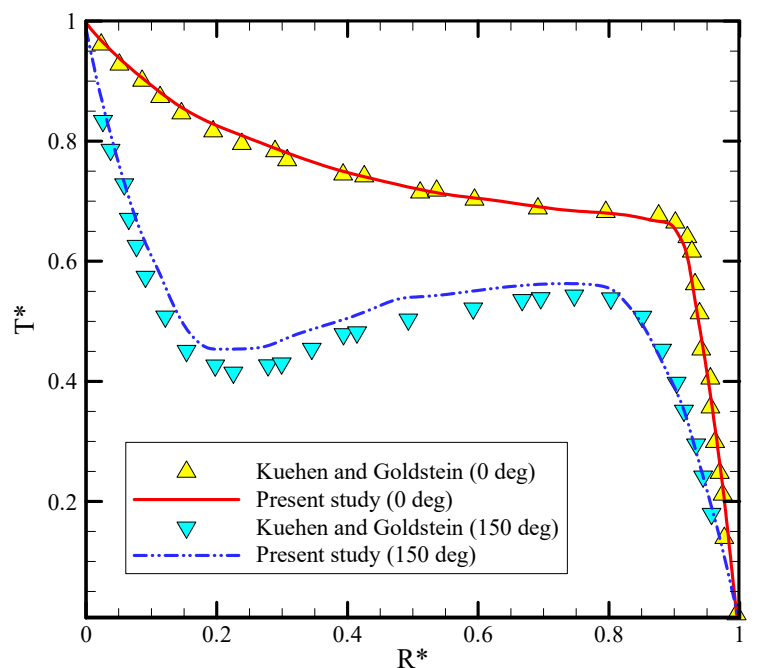

(b)

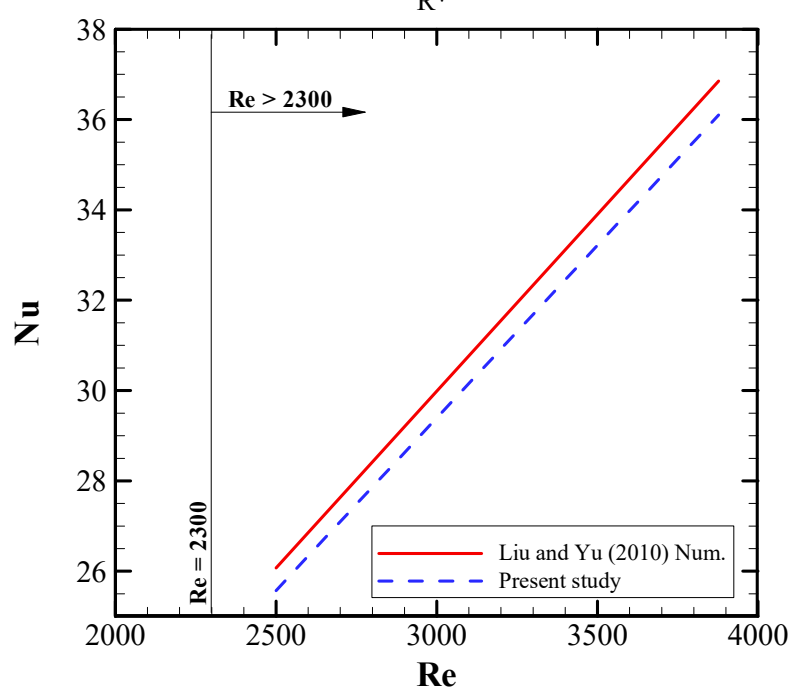

(c)
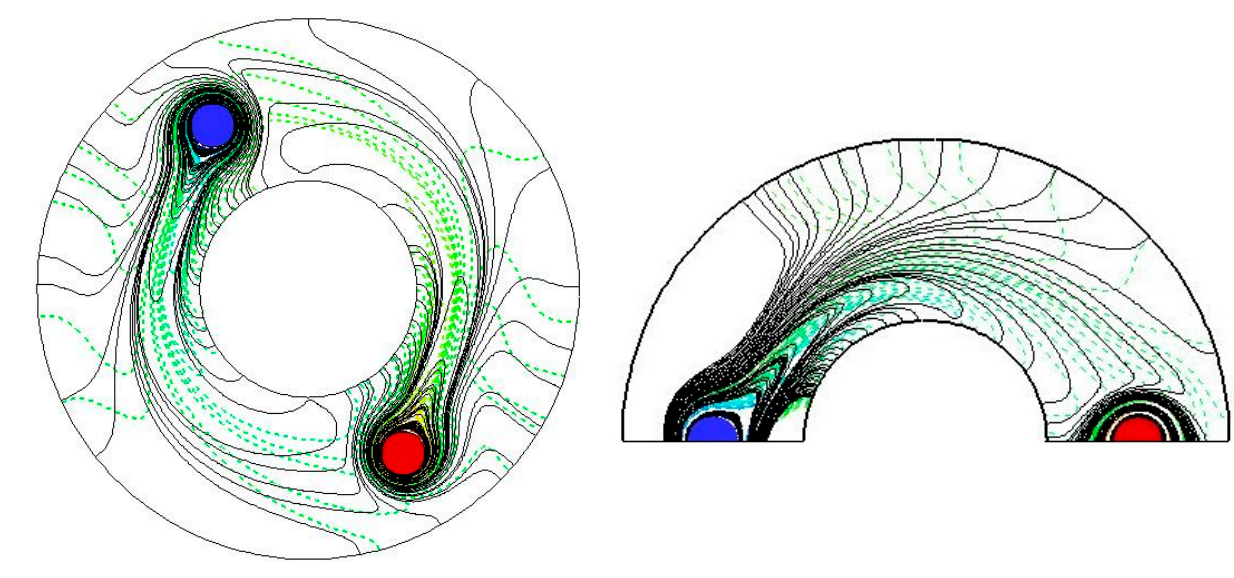

Figure 3. (a) Dimensionless temperature dissimilarity versus dimensionless distance to validate the obtained results in the present work and the empirical data of Kuehn and Goldstein [46]. (b) Code validation with numerical data of Liu and Yu [47] in transient regime flow. (c) Code validation for symmetry boundary condition.

\section{Results and Discussion}

Figure 4 illustrates streamlines and isotherm lines at different cross-sections of the studied cylinder for the case filled with $\mathrm{Al}_{2} \mathrm{O}_{3}-\mathrm{Cu} /$ water $\mathrm{HNF}$ at $\phi_{1}=0.05, \phi_{2}=0.01, \varepsilon=0.2$, and $\mathrm{Re}=3000$. As seen in this figure, HNF flow and heat transfer through the $\mathrm{z}$-direction of the cylinder are developed. 
Additionally, the calculations show that different vortexes are through the annulus. The main heat transfer mechanism in the annulus is convection and the next one is radiation. However, the portion of radiation heat transfer is sharply lower than the convective mechanism. In addition, the presence of rods leads to more heat transfer because of vortexes being made. Rods are like obstacles that destroy the laminar sublayers and make local turbulence which enhance the convective heat transfer coefficient in the annulus and intensify the $\mathrm{Nu}$. Figure 5 illustrates streamlines and isotherm lines at different cross-sections of the studied cylinder for the case filled with $\mathrm{Al}_{2} \mathrm{O}_{3}-\mathrm{Cu}$ /water $\mathrm{HNF}$ at $\phi_{1}=0.05$, $\phi_{2}=0.01, \varepsilon=0.2$, and $\operatorname{Re}=4000$. As seen in this figure, HNF flow and heat transfer through the z-direction of the cylinder are developed. Additionally, the calculations show that different vortexes are through the annulus. The main heat transfer mechanism in the annulus is convection and the next one is radiation. However, the portion of radiation heat transfer is sharply lower than the convective mechanism. Additionally, the presence of rods leads to more heat transfer because of vortexes being made. Rods are like obstacles that destroy the laminar sublayers and make local turbulence which enhance the convective heat transfer coefficient in the annulus and augment the $N u$. Additionally, it is realized that higher Reynolds numbers lead to more heat transfer coefficients because of more vortexes and turbulence through the cylindrical annulus. By comparing the streamlines and isotherm lines in Figures 4 and 5, some similarities between them are clearly seen.

Figure 6 illustrates the streamlines and isotherm lines at different cross-sections of the studied cylinder for the case filled with $\mathrm{Al}_{2} \mathrm{O}_{3}-\mathrm{Cu}$ /water $\mathrm{HNF}$ at $\phi_{1}=0.05, \phi_{2}=0.05, \varepsilon=0.2$, and $\mathrm{Re}=4000$. As seen in this figure, HNF flow and heat transfer through the z-direction of cylinder are developed. Additionally, the calculations show that different vortexes are through the annulus. The main heat transfer mechanism in the annulus is convection and the next one is radiation. However, the portion of radiation heat transfer is sharply lower than the convective mechanism. In addition, the presence of rods leads to more heat transfer because of vortexes being made. Rods are like obstacles that destroy the laminar sublayers and make local turbulence which enhance the convective heat transfer coefficient in the annulus and augment the $\mathrm{Nu}$. Furthermore, it is realized that higher volume concentrations of nanoparticles lead to more heat transfer coefficients because of the higher thermal conductivity of HNF flow and also more vortexes and turbulence through the cylindrical annulus because of more dynamic viscosity values. By comparing the streamlines and isotherm lines in Figures 5 and 6, some similarities between them are clearly seen.

Figure 7 illustrates the streamlines and isotherm lines at different cross-sections of the studied cylinder for the case filled with $\mathrm{Al}_{2} \mathrm{O}_{3}-\mathrm{Cu} /$ water $\mathrm{HNF}$ at $\phi_{1}=0.05, \phi_{2}=0.01, \varepsilon=0.7$, and $\mathrm{Re}=3000$. As seen in this figure, HNF flow and heat transfer through the z-direction of the cylinder are developed. Additionally, the calculations show that different vortexes are through the annulus. The main heat transfer mechanism in the annulus is convection and the next one is radiation. However, the portion of radiation heat transfer is sharply lower than the convective mechanism. In addition, the presence of rods leads to more heat transfer because of vortexes being made. Rods are like obstacles that destroy the laminar sublayers and make local turbulence which enhance the convective heat transfer coefficient in the annulus and augment the $\mathrm{Nu}$. Figure 8 illustrates streamlines and isotherm lines at different cross-sections of the studied cylinder for the case filled with $\mathrm{Al}_{2} \mathrm{O}_{3}-\mathrm{Cu}$ /water $\mathrm{HNF}$ at $\phi_{1}=0.05, \phi_{2}=0.01, \varepsilon=0.7$, and $\operatorname{Re}=4000$. As seen in this figure, HNF flow and heat transfer through the z-direction of cylinder are developed. Additionally, the calculations show that different vortexes are through the annulus. The main heat transfer mechanism in the annulus is convection and the next one is radiation. However, the portion of radiation heat transfer is sharply lower than the convective mechanism. Additionally, the presence of rods leads to more heat transfer because of vortexes being made. Rods are like obstacles that destroy the laminar sublayers and make local turbulence which enhance the convective heat transfer coefficient in the annulus and augment the Nu. Additionally, it is realized that higher Reynolds numbers lead to more heat transfer coefficients because of more vortexes and turbulence through the cylindrical annulus. By comparing the streamlines and isotherm lines in Figures 7 and 8, some similarities between them are clearly seen. As noted previously, the portion 
of radiation heat transfer inside the studied cylinder is significantly lower than the convection heat transfer. Therefore, variations in emissivity values do not have an important influence on HNF flow and heat transfer distribution inside the cylindrical annulus, which is shown clearly by comparing Figures 4-8 with each other. Higher emissivity values should lead to higher radiation heat transfer, but the portion of radiative heat transfer in the studied annulus is low and therefore, does not have an observable increment in HNF flow and heat transfer.
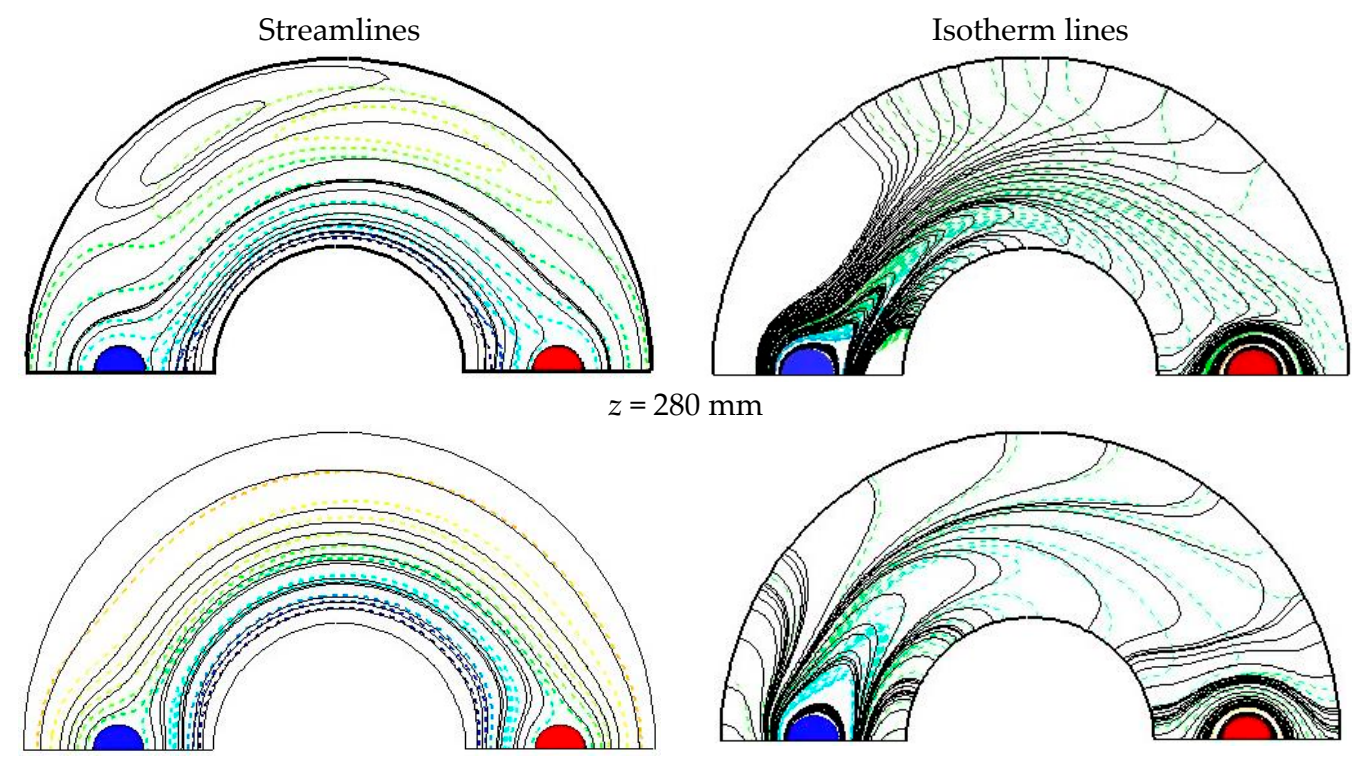

$z=220 \mathrm{~mm}$

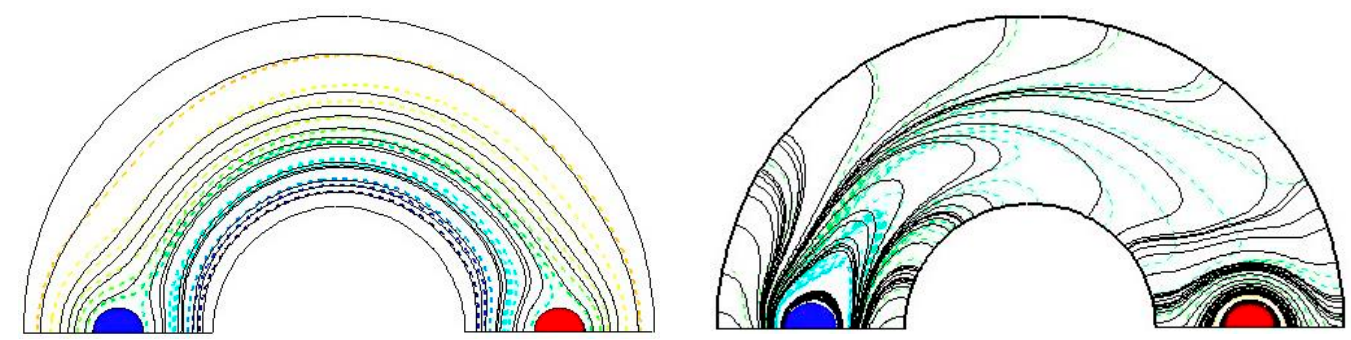

$z=150 \mathrm{~mm}$
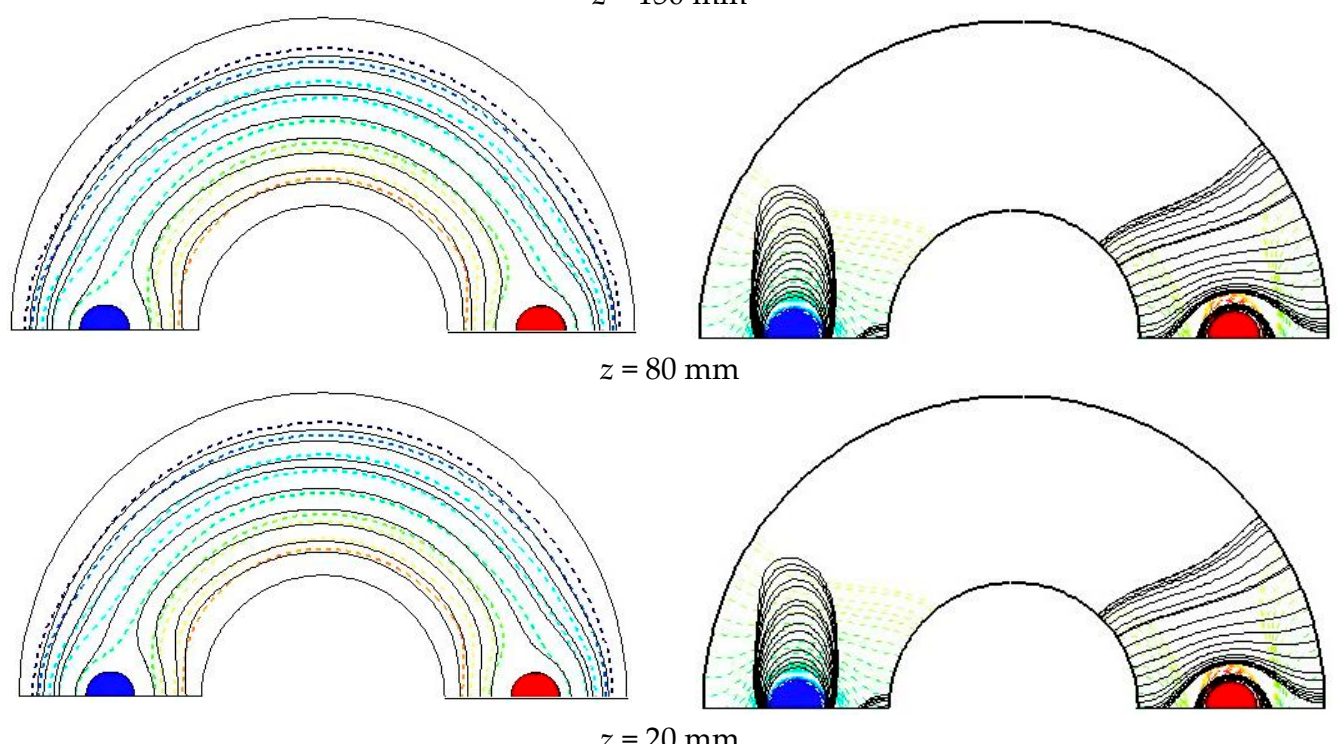

$z=20 \mathrm{~mm}$

Figure 4. Streamlines and isotherm lines at different cross-sections of the studied cylinder for the case filled with $\mathrm{Al}_{2} \mathrm{O}_{3}-\mathrm{Cu} /$ water $\mathrm{HNF}$ at $\phi_{1}=0.05, \phi_{2}=0.01, \varepsilon=0.2$, and $\mathrm{Re}=3000$. 


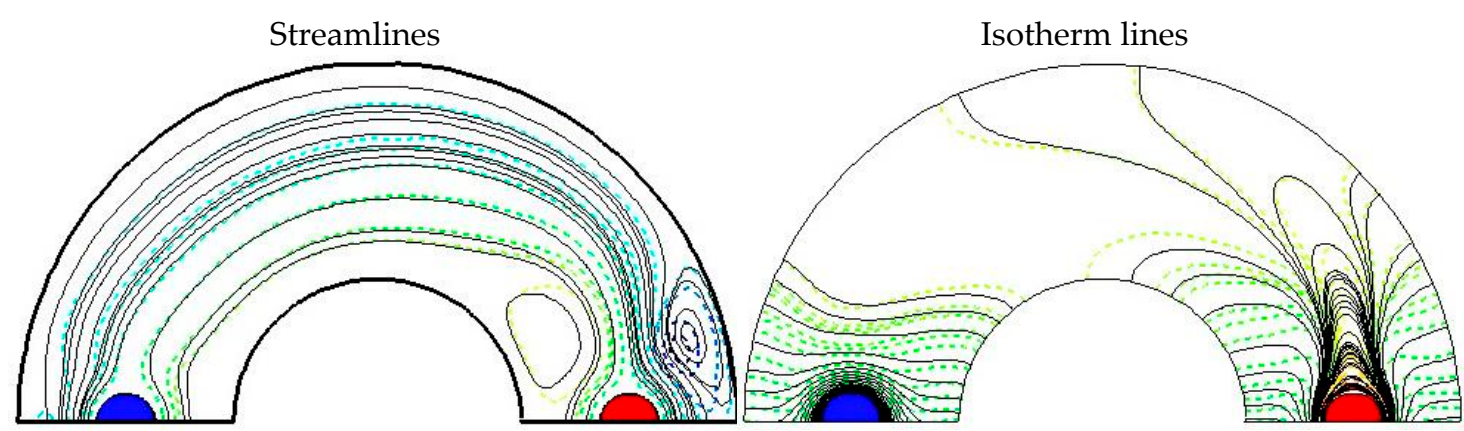

$z=280 \mathrm{~mm}$

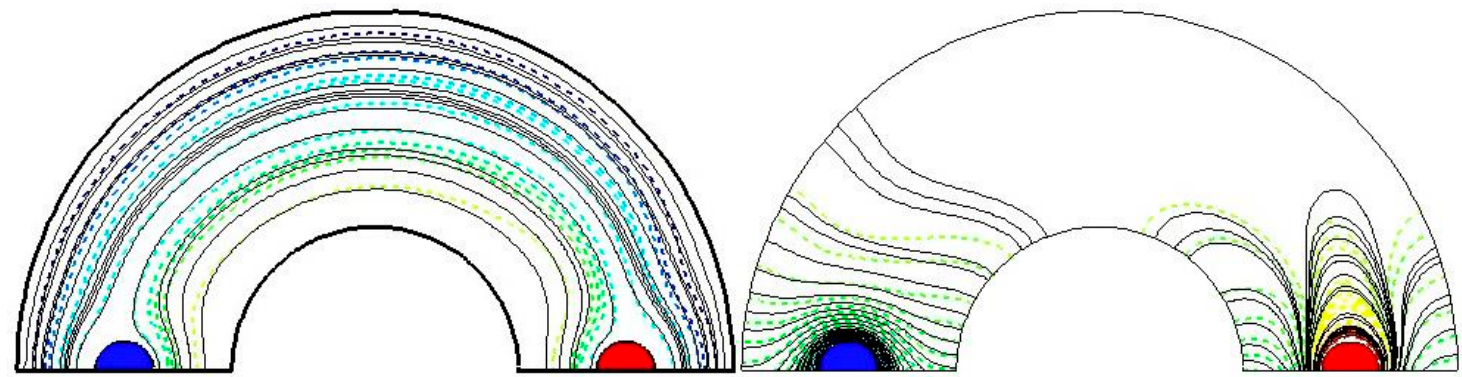

$z=220 \mathrm{~mm}$

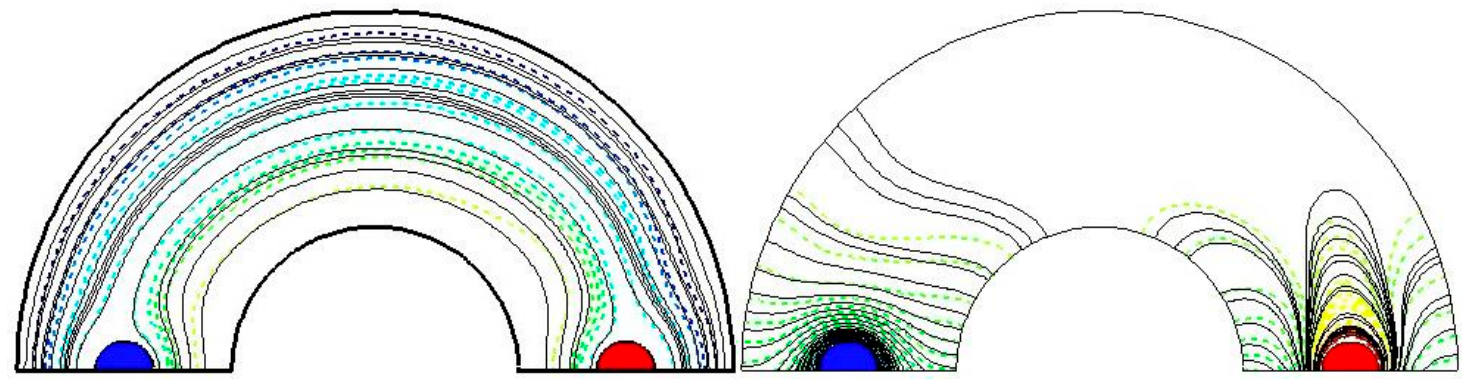

$z=150 \mathrm{~mm}$
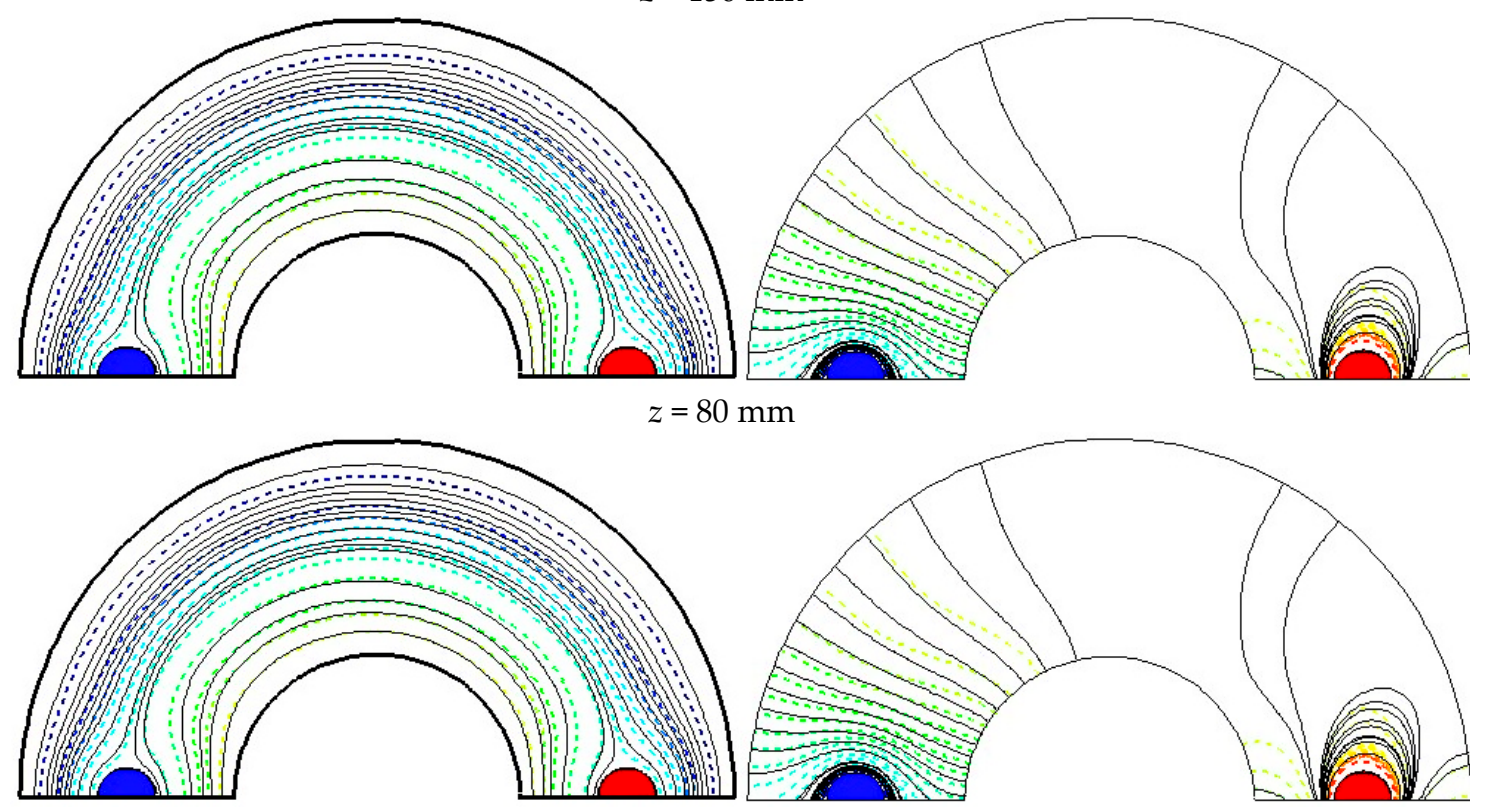

$z=20 \mathrm{~mm}$

Figure 5. Streamlines and isotherm lines at different cross-sections of the studied cylinder for the case filled with $\mathrm{Al}_{2} \mathrm{O}_{3}-\mathrm{Cu} /$ water $\mathrm{HNF}$ at $\phi_{1}=0.05, \phi_{2}=0.01, \varepsilon=0.2$, and $\mathrm{Re}=4000$. 

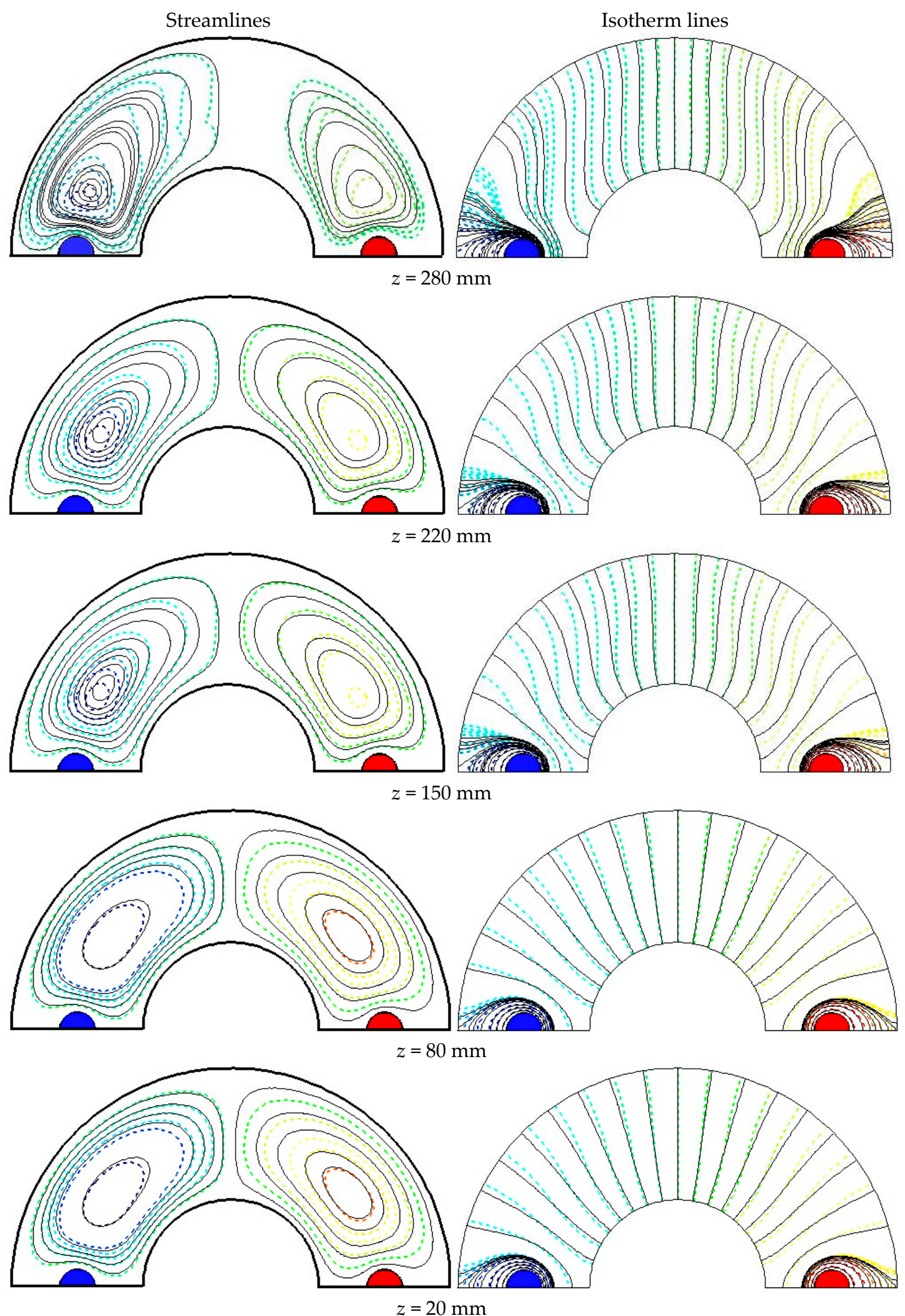

Figure 6. Streamlines and isotherm lines at different cross-sections of the studied cylinder for the case filled with $\mathrm{Al}_{2} \mathrm{O}_{3}-\mathrm{Cu} /$ water $\mathrm{HNF}$ at $\phi_{1}=0.05, \phi_{2}=0.05, \varepsilon=0.2$, and $\mathrm{Re}=4000$. 

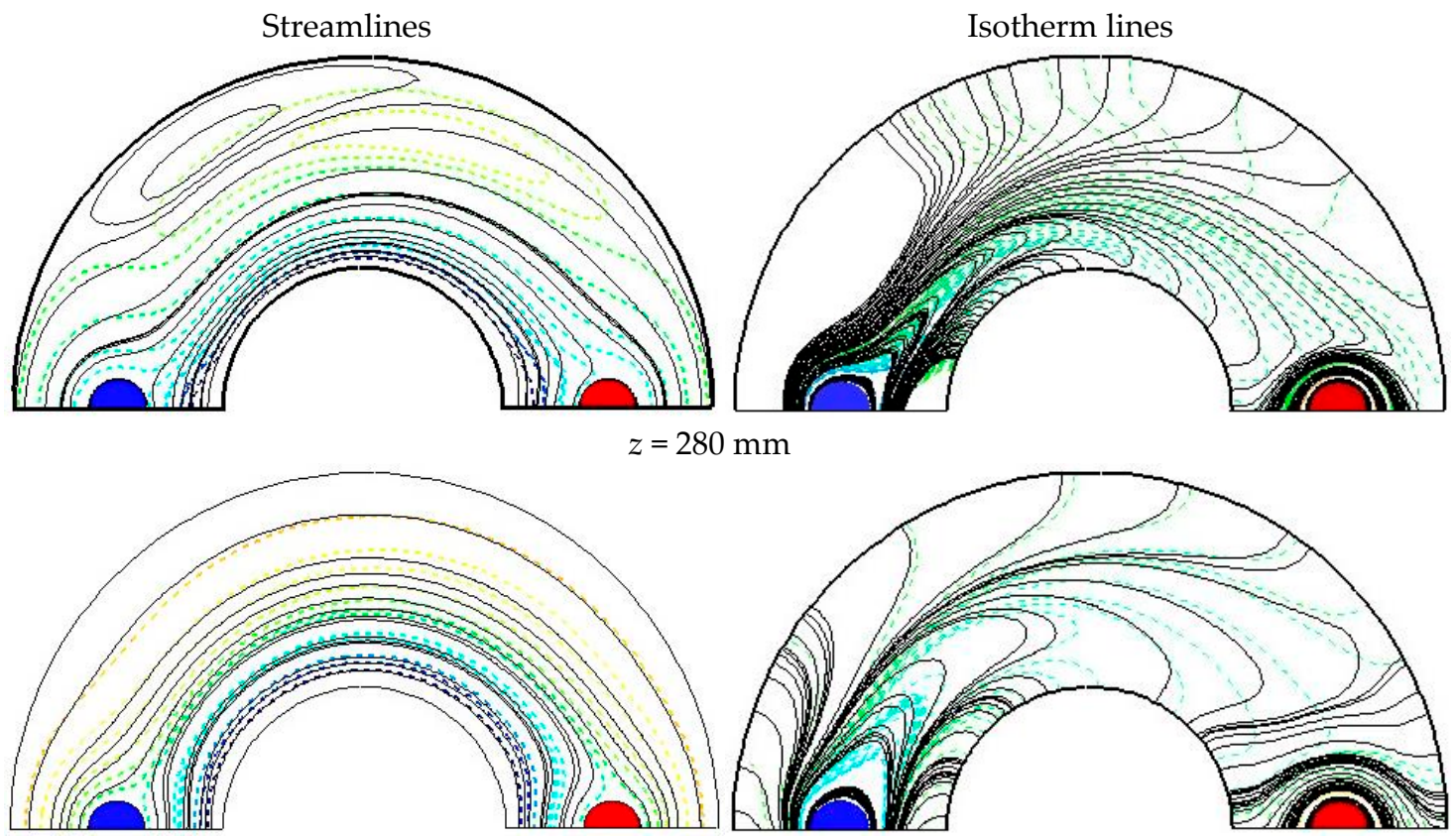

$z=220 \mathrm{~mm}$

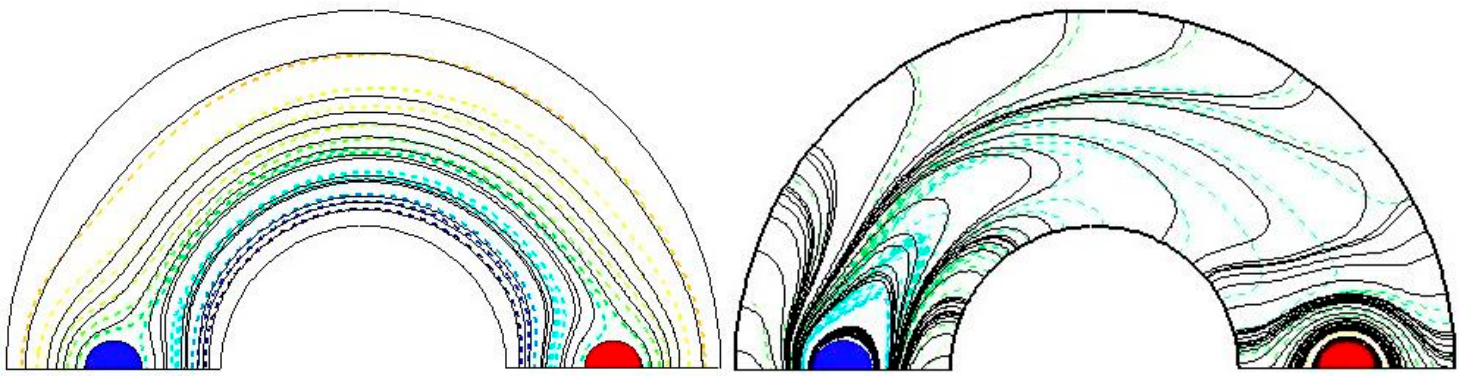

$z=150 \mathrm{~mm}$

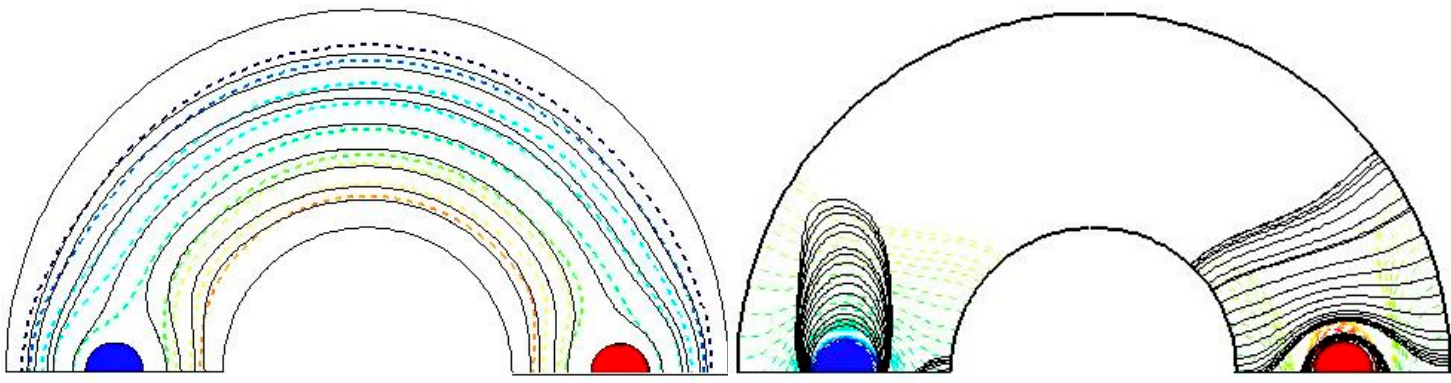

$z=80 \mathrm{~mm}$

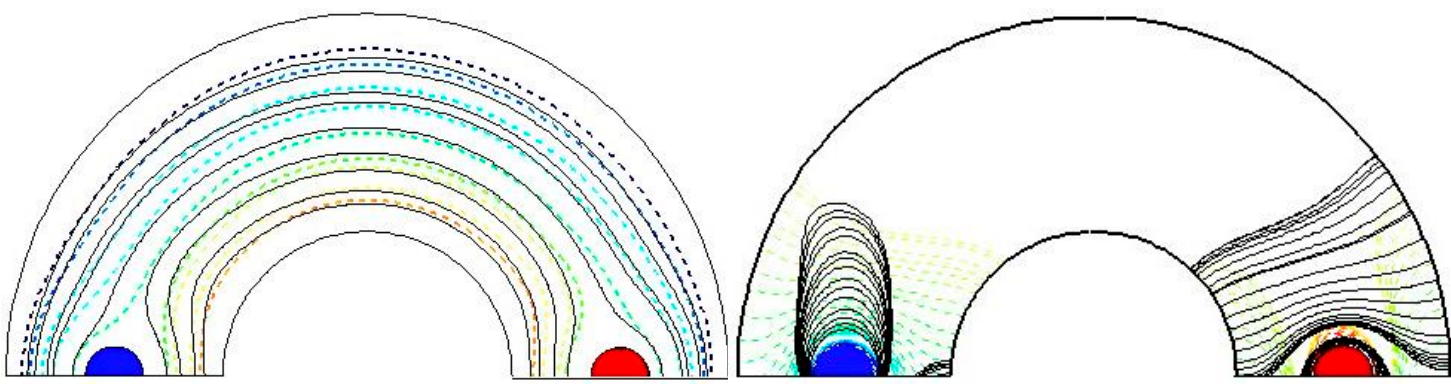

$z=20 \mathrm{~mm}$

Figure 7. Streamlines and isotherm lines at different cross-sections of the studied cylinder for the case filled with $\mathrm{Al}_{2} \mathrm{O}_{3}-\mathrm{Cu} /$ water $\mathrm{HNF}$ at $\phi_{1}=0.05, \phi_{2}=0.01, \varepsilon=0.7$, and $\mathrm{Re}=3000$. 


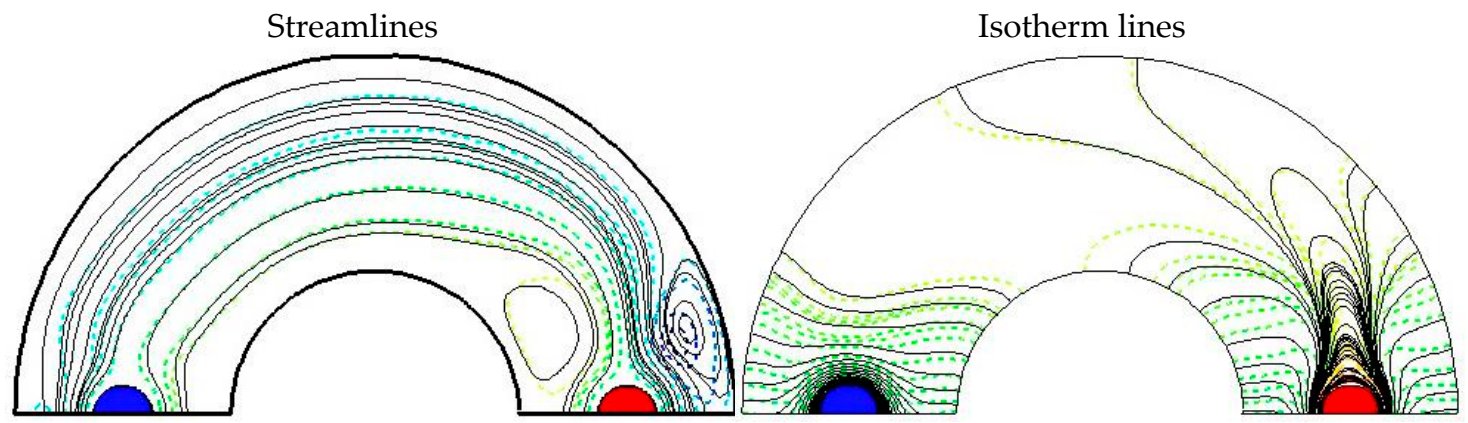

$z=280 \mathrm{~mm}$

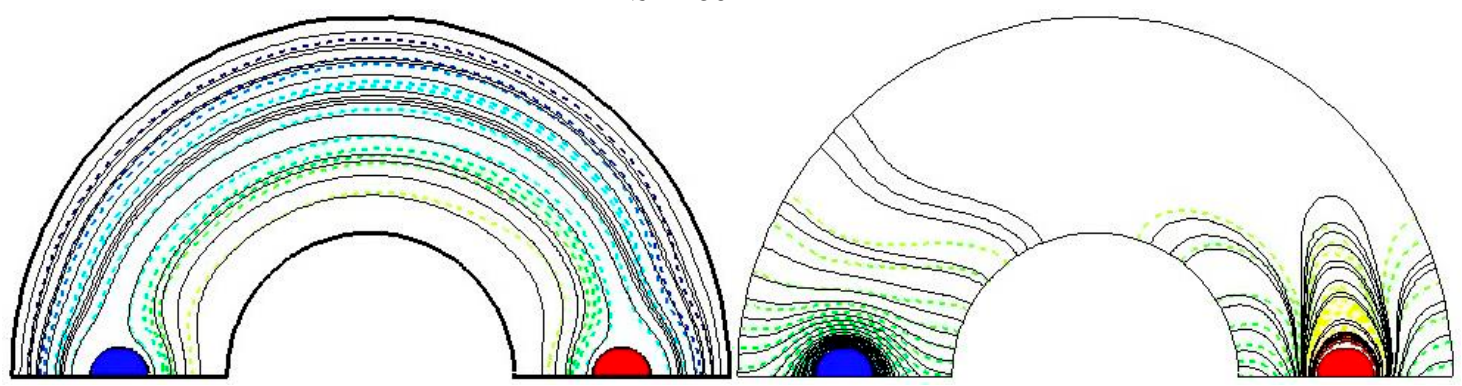

$z=220 \mathrm{~mm}$

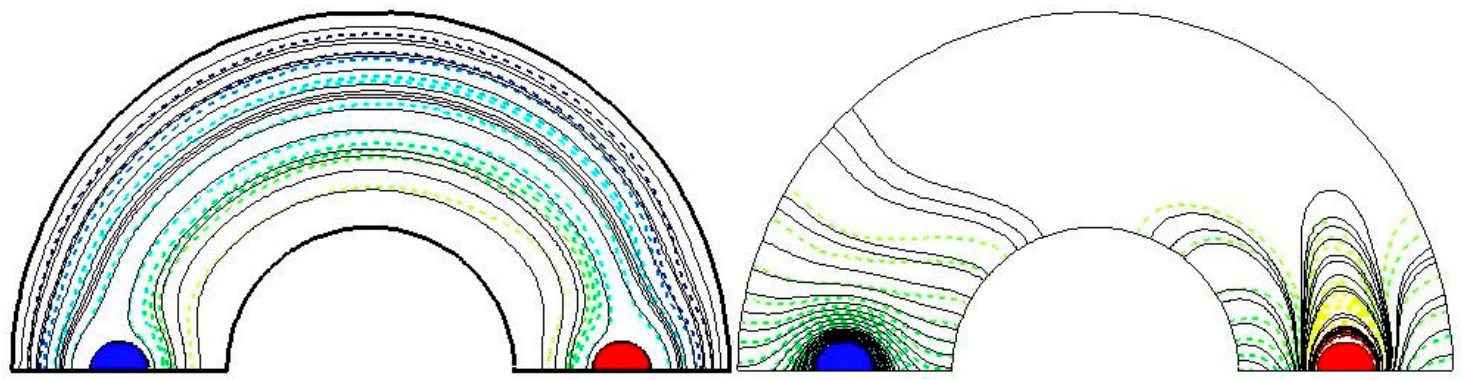

$z=150 \mathrm{~mm}$

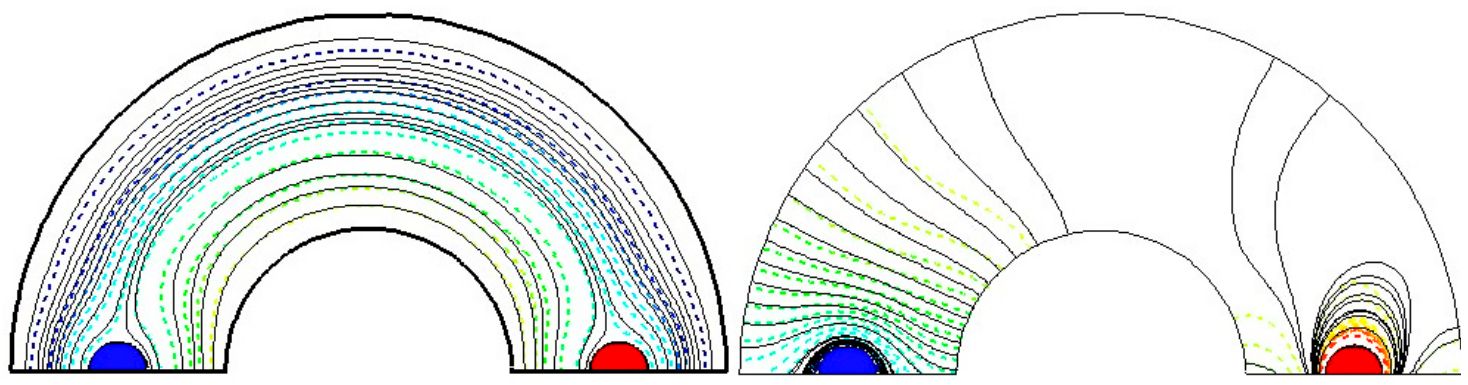

$z=80 \mathrm{~mm}$

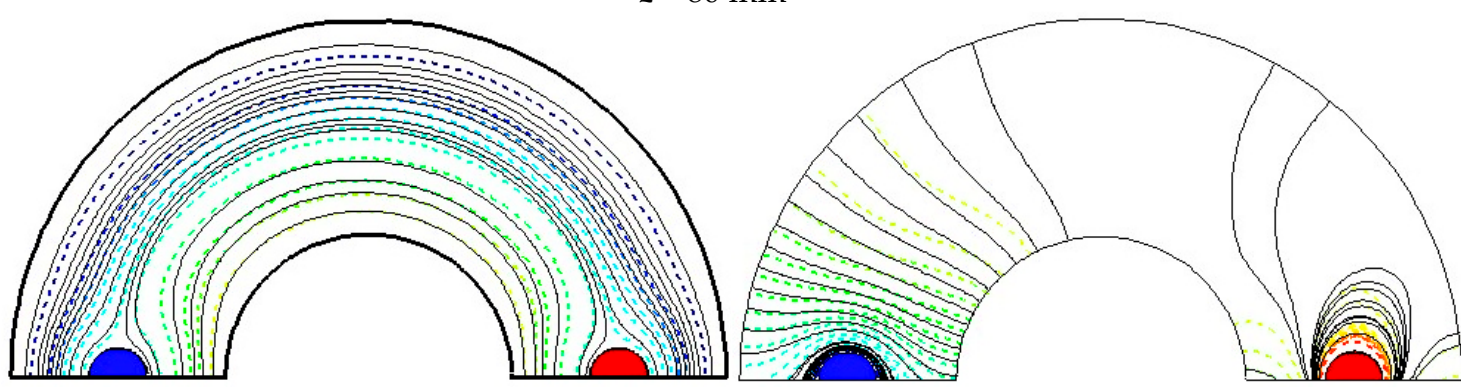

$z=20 \mathrm{~mm}$

Figure 8. Streamlines and isotherm lines at different cross-sections of the studied cylinder for the case filled with $\mathrm{Al}_{2} \mathrm{O}_{3}-\mathrm{Cu} /$ water $\mathrm{HNF}$ at $\phi_{1}=0.05, \phi_{2}=0.01, \varepsilon=0.7$, and $\mathrm{Re}=4000$. 
Figure 9 illustrates streamlines and isotherm lines at different cross-sections of the studied cylinder for the case filled with $\mathrm{Al}_{2} \mathrm{O}_{3}-\mathrm{Cu}$ /water $\mathrm{HNF}$ at $\phi_{1}=0.05, \phi_{2}=0.05, \varepsilon=0.7$ and $\mathrm{Re}=4000$. As seen in this figure, HNF flow and heat transfer through the z-direction of the cylinder are developed. Additionally, the calculations show different vortexes are through the annulus. The main heat transfer mechanism in the annulus is convection and the next one is radiation. However, the portion of radiation heat transfer is sharply lower than the convective mechanism. Additionally, the presence of rods leads to more heat transfer because of vortexes being made. Rods are like obstacles that destroy the laminar sublayers and make local turbulence which enhance the convective heat transfer coefficient in the annulus and augment the $N u$. In addition, it is realized that higher volume concentrations of nanoparticles lead to more heat transfer coefficients because of more thermal conductivity of HNF flow and also, more vortexes and turbulence through the cylindrical annulus because of more dynamic viscosity values. By comparing the streamlines and isotherm lines in Figures 6 and 9, some similarities between them are clearly seen. As noted previously, the portion of radiation heat transfer inside the studied cylinder is significantly lower than the convection heat transfer. Therefore, variations in emissivity values do not have an important influence on HNF flow and heat transfer distribution inside the cylindrical annulus, which is shown clearly by comparing Figures 6 and 9 with each other. Higher emissivity values should lead to higher radiation heat transfer, but the portion of radiative heat transfer in the studied annulus is low and therefore, does not have an observable increment in HNF flow and heat transfer.

Figure 10 demonstrates the effects of using different base fluids on variation of predicted $N u_{\text {ave }}$ versus different volume fractions of $\mathrm{Cu}$ nanoparticles for the studied cylinder for the case filled with $\mathrm{Al}_{2} \mathrm{O}_{3}-\mathrm{Cu} \mathrm{HNF}$ at $\phi_{1}=0.05$ or $0.10, \varepsilon=0.2$, and $\mathrm{Re}=3000$ or 4000 . As seen in Figure 10a, for the model at $\operatorname{Re}=3000$ and $\phi_{1}=0.05$, all studied cases with different base fluids have similar behavior. For all studied cases, the total $N u_{\text {ave }}$ reduces firstly by an increment of the volume concentrations of $\mathrm{Cu}$ nanoparticles until $\phi_{2}=0.01$ or 0.02 and then, the total $N u_{\text {ave }}$ rises by an increment of the volume concentrations of $\mathrm{Cu}$ nanoparticles. Additionally, it is seen that for the case with water as the base fluid, the total $N u_{\text {ave }}$ at $\phi_{2}=0.05$ is more than the values at $\phi_{2}=0.00$, while for the other cases, the total $N u_{\text {ave }}$ at $\phi_{2}=0.05$ is less than the values at $\phi_{2}=0.00$. Furthermore, for all studied cases, the case with water as the base fluid has the maximum $N u_{\text {ave }}$. As seen in Figure 10b, for the model at $\operatorname{Re}=4000$ and $\phi_{1}=0.05$, all studied cases with different base fluids have similar behavior. For all studied cases, the total $N u_{\text {ave }}$ reduces firstly by an increment of the volume concentrations of $\mathrm{Cu}$ nanoparticles until $\phi_{2}=0.01$ and then, the total $N u_{\text {ave }}$ rises by an increment of the volume concentrations of $\mathrm{Cu}$ nanoparticles. Additionally, it is seen that for the case with water as the base fluid, the total $N u_{\text {ave }}$ at $\phi_{2}=0.05$ is more than the values at $\phi_{2}=0.00$, while for the other cases, the total $N u_{\text {ave }}$ at $\phi_{2}=0.05$ is less than the values at $\phi_{2}=0.00$. Additionally, it is seen that by increment of Reynolds numbers, the $N u_{\text {ave }}$ augments, as found by the comparison of Figure 10a,b. 

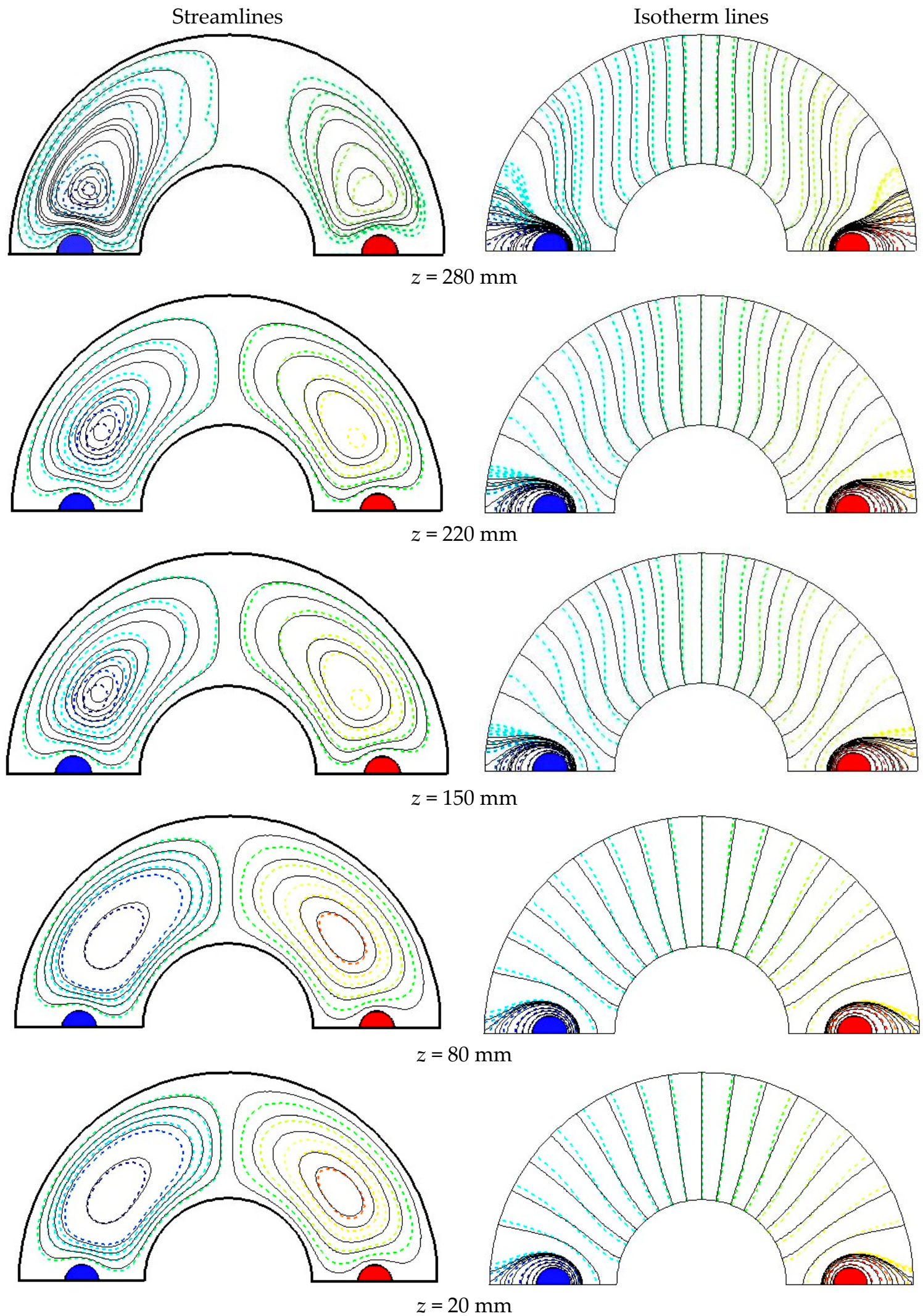

Figure 9. Streamlines and isotherm lines at different cross-sections of the studied cylinder for the case filled with $\mathrm{Al}_{2} \mathrm{O}_{3}-\mathrm{Cu} /$ water $\mathrm{HNF}$ at $\phi_{1}=0.05, \phi_{2}=0.05, \varepsilon=0.7$, and $\mathrm{Re}=4000$. 
As seen in Figure 10c, for the model at $\operatorname{Re}=3000$ and $\phi_{1}=0.10$, all studied cases with different base fluids have similar behavior. For all studied cases, the total $N u_{\text {ave }}$ increases firstly by an increment of the volume concentrations of $\mathrm{Cu}$ nanoparticles until $\phi_{2}=0.01,0.02$, or 0.03 and then, the total $N u_{\text {ave }}$ diminishes by the intensification of volume concentrations of $\mathrm{Cu}$ nanoparticles. Additionally, it is seen that for the case with water as the base fluid, the total $N u_{\text {ave }}$ at $\phi_{2}=0.05$ is more than the values at $\phi_{2}=0.00$, while for the other cases, the total $N u_{\text {ave }}$ at $\phi_{2}=0.05$ is less than the values at $\phi_{2}=0.00$. Furthermore, for all studied cases, the highest $N u_{\text {ave }}$ belongs to the case with water as the base fluid. As seen in Figure 10d, for the model at $\operatorname{Re}=4000$ and $\phi_{1}=0.10$, all studied cases with different base fluids have similar behavior. For all studied cases, the total $N u_{\text {ave }}$ reduces firstly by an increment of the volume concentrations of $\mathrm{Cu}$ nanoparticles until $\phi_{2}=0.01,0.02$, and 0.03 , and then, the total $N u_{\text {ave }}$ rises by an increment of the volume concentrations of $\mathrm{Cu}$ nanoparticles. Additionally, it is seen that for the case with water as the base fluid, the total $N u_{\text {ave }}$ at $\phi_{2}=0.05$ is more than the values at $\phi_{2}=0.00$, while for the other cases, the total $N u_{\text {ave }}$ at $\phi_{2}=0.05$ is less than the values at $\phi_{2}=0.00$. Furthermore, for all studied cases, the case with water as the base fluid has the maximum $N u_{\text {ave }}$. Additionally, it is seen that by increment of Reynolds numbers, the $N u_{\text {ave }}$ augments, as found by the comparison of Figure 10c,d.

Figure 11 shows different portions of the predicted $N u$ versus different volume fractions of $\mathrm{Cu}$ nanoparticles of the studied cylinder for the case filled with ethylene glycol-based HNF at $\phi_{1}=0.05$, $\varepsilon=0.2$, and $\operatorname{Re}=3000$. It is seen that just about 5 to $7 \%$ of the total average Nusselt number is related to radiation heat transfer and a huge portion is related to convection heat transfer. This is why variations of emissivity coefficient do not have a significant effect on the final results.

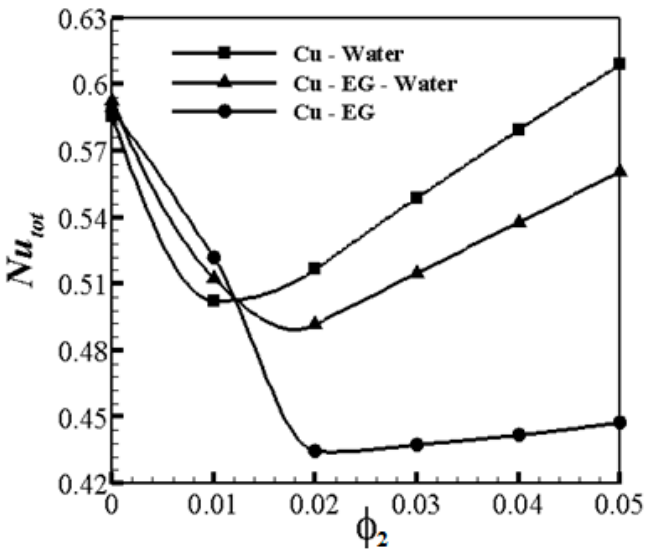

(a) $\operatorname{Re}=3000$ and $\phi_{1}=0.05$

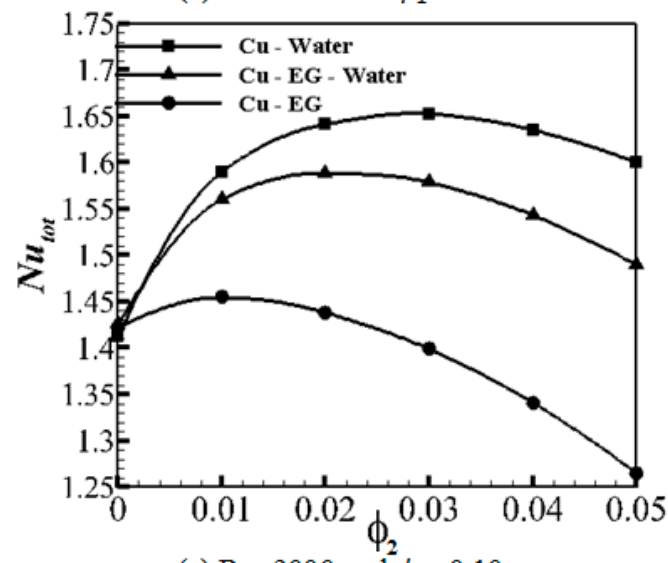

(c) $\mathrm{Re}=3000$ and $\phi_{1}=0.10$

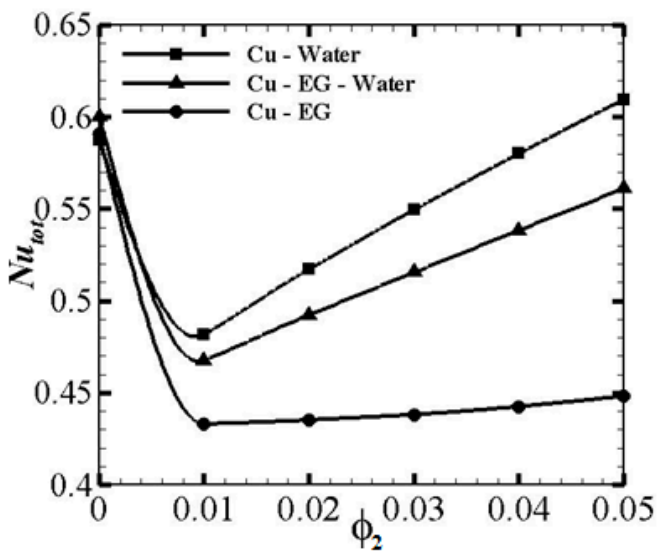

(b) $\mathrm{Re}=4000$ and $\phi_{1}=0.05$

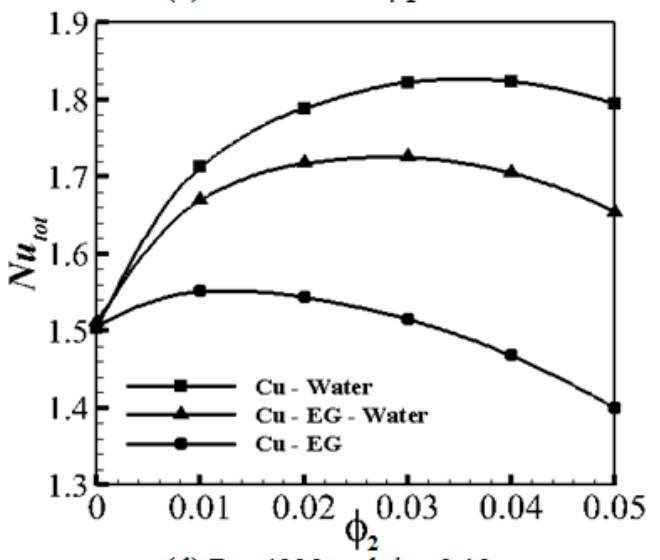

(d) $\mathrm{Re}=4000$ and $\phi_{1}=0.10$

Figure 10. Effects of using different base fluids on variation of predicted $N u_{\text {ave }}$ versus different volume fractions of $\mathrm{Cu}$ nanoparticles of the studied cylinder for the case filled with $\mathrm{Al}_{2} \mathrm{O}_{3}-\mathrm{Cu} \mathrm{HNF}$ at $\phi_{1}=0.05$ or $0.10, \varepsilon=0.2$, and $\operatorname{Re}=3000$ or 4000 . 


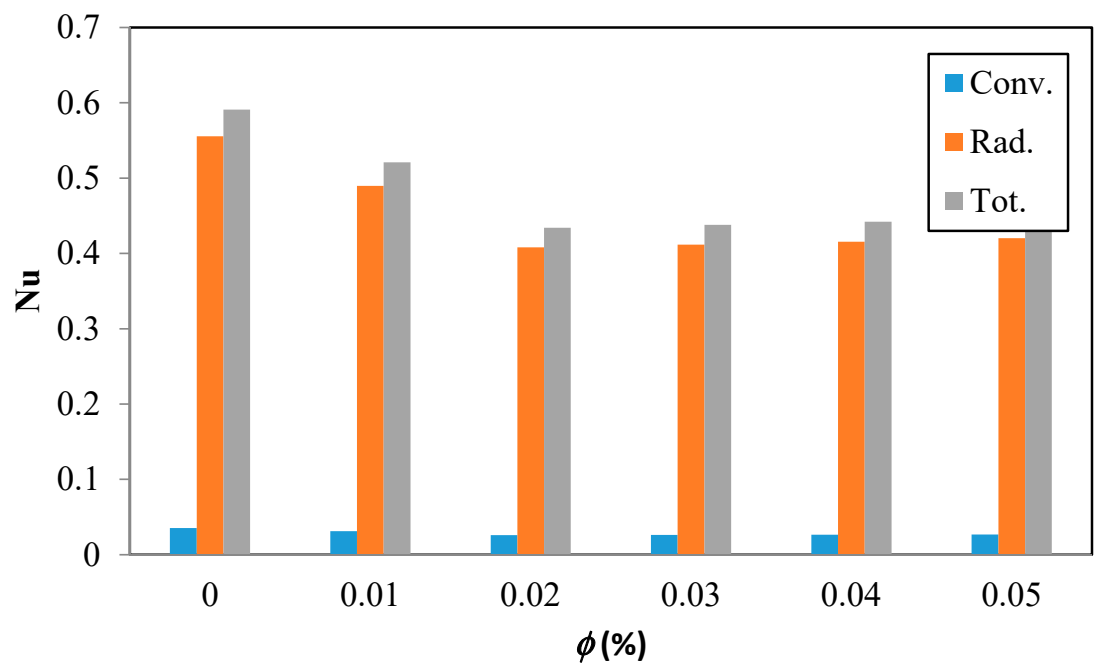

Figure 11. Different portions of the predicted $\mathrm{Nu}$ versus different volume fractions of $\mathrm{Cu}$ nanoparticles of the studied cylinder for the case filled with EG-based HNF at $\phi_{1}=0.05, \varepsilon=0.2$, and $\operatorname{Re}=3000$.

\section{Conclusions}

The present paper investigates symmetry simulation of transient forced HNF flow and heat transfer in a three-dimensional annulus equipped with hot and cold rods. The chief goal of the current study is to model the geometry using a symmetry scheme and also examine the influences of dissimilar Reynolds numbers, emissivity coefficients, and dissimilar volume fractions of nanoparticles on the thermal and hydraulic characteristics of the studied annulus. The height of cylinder is changed from $300 \mathrm{~mm}$. Additionally, the height of square is changed from 46.03 to $70.71 \mathrm{~mm}$, the length of square is $1000 \mathrm{~mm}$, and the gravity influences are determined in $z$ direction. The system is made of an insulator in the center and outer sides of the cylinder, with a boundary condition of zero heat flux. However, this material is assumed with two different emissivity values, $\varepsilon=0.2$ and $\varepsilon=0.5$, in order to analyze the effects of emissivity values on radiation heat transfer, in addition to two different Reynolds numbers, $\mathrm{Re}=3000$ and 4000 . For all studied models, the initial NF temperature is $T_{\text {initial }}=350 \mathrm{~K}$ and the cold side temperature is $T_{c}=300 \mathrm{~K}$. The hot side temperature can be $T_{h}=430 \mathrm{~K}$. The heat transfer fluid is a water-, ethylene-glycol- or water/ethylene-glycol mixture-based $\mathrm{Cu}-\mathrm{Al}_{2} \mathrm{O}_{3} \mathrm{HNF}$, which makes a Newtonian NF. The RANS equations with the shear-stress (SST) $k-\omega$ turbulence model have been used for simulating the turbulence regime. The most important obtained results are as follows:

- For the model at $\operatorname{Re}=3000$ and $\phi_{1}=0.05$, all studied cases with different base fluids have similar behavior. For all studied cases, the total $N u_{\text {ave }}$ reduces firstly by an increment of the volume concentrations of $\mathrm{Cu}$ nanoparticles until $\phi_{2}=0.01$ or 0.02 and then, the total $N u_{\text {ave }}$ rises by an increment of the volume concentrations of $\mathrm{Cu}$ nanoparticles.

- For the case with water as the base fluid, the total $N u_{\text {ave }}$ at $\phi_{2}=0.05$ is more than the values at $\phi_{2}=0.00$, while for the other cases, the total $N u_{\text {ave }}$ at $\phi_{2}=0.05$ is less than the values at $\phi_{2}=0.00$.

- For all studied cases, the case with water as the base fluid has the maximum $N u_{\text {ave }}$.

- For the model at $\operatorname{Re}=4000$ and $\phi_{1}=0.05$, all studied cases with different base fluids have similar behavior. For all studied cases, the total $N u_{\text {ave }}$ reduces firstly by an increment of the volume concentrations of $\mathrm{Cu}$ nanoparticles until $\phi_{2}=0.01$ and then, the total $N u_{\text {ave }}$ rises by an increment of the volume concentrations of $\mathrm{Cu}$ nanoparticles.

- By increment of Reynolds numbers, the $N u_{\text {ave }}$ augments.

- Higher emissivity values should lead to higher radiation heat transfer, but the portion of radiative heat transfer in the studied annulus is low and therefore, does not have an observable increment in HNF flow and heat transfer. 
Author Contributions: Conceptualization, A.S.G.; methodology, M.B.; software, A.S.G. and B.H.; validation, B.H.; formal analysis, A.K.H.; investigation, A.K.H.; resources, A.K.H.; data curation, S.R.; writing-original draft preparation, S.R.; writing — review and editing, S.R.; visualization, M.B.; supervision, M.S.S.; project administration, M.S.S. All authors have read and agreed to the published version of the manuscript.

Funding: This research received no external funding.

Acknowledgments: M. S. Shadloo acknowledges the access to French HPC resources provided by the French regional computing center of Normandy CRIANN (2017002).

Conflicts of Interest: The authors declare no conflict of interest.

\section{Nomenclature}

$\begin{array}{ll}c_{p} & \text { Specific heat }(\mathrm{J} / \mathrm{kg} \cdot \mathrm{K}) \\ \mathrm{Cu} & \text { Copper } \\ d_{n p} & \text { Nanoparticles size } \\ \vec{g} & \text { Gravity } \\ k & \text { Thermal conductivity }(\mathrm{W} / \mathrm{m} \cdot \mathrm{K}) \\ \mathrm{Ra} & \text { Rayleigh number } \\ M & \text { Molecular weight of the base fluid } \\ N & \text { Avogadro number } \\ \mathrm{Nu} & \text { Nusselt number } \\ \vec{P} & \text { Pressure } \\ T_{c} & \text { Cold side temperature } \\ T_{f r} & \text { liquid freezing point of base fluid } \\ T_{h} & \text { Hot side temperature } \\ T_{i n i t i a l} & \text { Initial nanofluid temperature } \\ T_{m} & \text { Each section-temperature } \\ \vec{U}_{d r, b f} & \text { Nanoparticles drift velocity } \\ \overrightarrow{U_{d r}} & \text { Base fluid drift velocity } \\ u_{B} & \text { Average Brownian velocity } \\ G r e e k \text { Symbols } & \\ \vec{\alpha} & \text { Acceleration } \\ \rho & \text { Density (kg/m }{ }^{3} \text { ) } \\ \varepsilon & \text { emissivity } \\ \phi & \text { volume concentration of nanoparticles } \\ \mu & \text { Dynamic viscosity } \\ & \end{array}$

\section{References}

1. Shahsavar, A.; Shaham, A.; Talebizadehsardari, P. Wavy channels triple-tube LHS unit with sinusoidal variable wavelength in charging/discharging mechanism. Int. Commun. Heat Mass Transf. 2019, 107, 93-105. [CrossRef]

2. Al-Rashed, A.A.; Shahsavar, A.; Rasooli, O.; Moghimi, M.; Karimipour, A.; Tran, M.D. Numerical assessment into the hydrothermal and entropy generation characteristics of biological water-silver nano-fluid in a wavy walled microchannel heat sink. Int. Commun. Heat Mass Transf. 2019, 104, 118-126. [CrossRef]

3. Shahsavar, A.; Al-Rashed, A.A.; Entezari, S.; Talebizadehsardari, P. Melting and solidification characteristics of a double-pipe latent heat storage system with sinusoidal wavy channels embedded in a porous medium. Energy 2019, 171, 751-769. [CrossRef]

4. Rostami, S.; Shahsavar, A.; Kefayati, G.; Goldanlou, A.S. Energy and Exergy Analysis of Using Turbulator in a Parabolic Trough Solar Collector Filled with Mesoporous Silica Modified with Copper Nanoparticles Hybrid Nanofluid. Energies 2020, 13, 2946. [CrossRef]

5. Yan, S.-R.; Moria, H.; Pourhedayat, S.; Hashemian, M.; Asaadi, S.; Dizaji, H.S.; Jermsittiparsert, K. A critique of effectiveness concept for heat exchangers; theoretical-experimental study. Int. J. Heat Mass Transf. 2020, 159, 120160. [CrossRef] 
6. Yi, Y.; Xie, X.; Jiang, Y. Optimization of solution flow rate and heat transfer area allocation in the two-stage absorption heat exchanger system based on a complete heat and mass transfer simulation model. Appl. Therm. Eng. 2020, 178, 115616. [CrossRef]

7. Yildiz, C.; Arici, M.; Nizetic, S.; Shahsavar, A. Numerical investigation of natural convection behavior of molten PCM in an enclosure having rectangular and tree-like branching fins. Energy 2020, 207, 118223. [CrossRef]

8. Shahsavar, A.; Rashidi, M.; Mosghani, M.M.; Toghraie, D.; Talebizadehsardari, P. A numerical investigation on the influence of nanoadditive shape on the natural convection and entropy generation inside a rectangle-shaped finned concentric annulus filled with boehmite alumina nanofluid using two-phase mixture model. J. Therm. Anal. Calorim. 2019, 141, 915-930. [CrossRef]

9. Ma, Y.; Shahsavar, A.; Talebizadehsardari, P. Two-phase mixture simulation of the effect of fin arrangement on first and second law performance of a bifurcation microchannels heatsink operated with biologically prepared water-Ag nanofluid. Int. Commun. Heat Mass Transf. 2020, 114, 104554. [CrossRef]

10. Zhang, R.; Aghakhani, S.; Pordanjani, A.H.; Vahedi, S.M.; Shahsavar, A.; Afrand, M. Investigation of the entropy generation during natural convection of Newtonian and non-Newtonian fluids inside the L-shaped cavity subjected to magnetic field: Application of lattice Boltzmann method. Eur. Phys. J. Plus 2020, 135, 184. [CrossRef]

11. Liu, W.; Shahsavar, A.; Barzinjy, A.A.; Al-Rashed, A.A.; Afrand, M. Natural convection and entropy generation of a nanofluid in two connected inclined triangular enclosures under magnetic field effects. Int. Commun. Heat Mass Transf. 2019, 108, 104309. [CrossRef]

12. Alsarraf, J.; Rahmani, R.; Shahsavar, A.; Afrand, M.; Wongwises, S. Effect of magnetic field on laminar forced convective heat transfer of MWCNT-Fe3O4/water hybrid nanofluid in a heated tube. J. Therm. Anal. Calorim. 2019, 137, 1809-1825. [CrossRef]

13. Zheng, Y.; Shahsavar, A.; Afrand, M. Sonication time efficacy on Fe3O4-liquid paraffin magnetic nanofluid thermal conductivity: An experimental evaluation. Ultrason. Sonochemistry 2020, 64, 105004. [CrossRef] [PubMed]

14. Alsarraf, J.; Shahsavar, A.; Khaki, M.; Ranjbarzadeh, R.; Karimipour, A.; Afrand, M. Numerical investigation on the effect of four constant temperature pipes on natural cooling of electronic heat sink by nanofluids: A multifunctional optimization. Adv. Powder Technol. 2020, 31, 416-432. [CrossRef]

15. Al-Rashed, A.A.A.A.; Rahimi-Nasrabadi, M.; Aghaei, A.; Monfared, F.; Shahsavar, A.; Afrand, M. Effect of a porous medium on flow and mixed convection heat transfer of nanofluids with variable properties in a trapezoidal enclosure. J. Therm. Anal. Calorim. 2019, 139, 741-754. [CrossRef]

16. Chen, Z.; Shahsavar, A.; Al-Rashed, A.A.; Afrand, M. The impact of sonication and stirring durations on the thermal conductivity of alumina-liquid paraffin nanofluid: An experimental assessment. Powder Technol. 2020, 360, 1134-1142. [CrossRef]

17. Shahsavar, A.; Baseri, M.M.; Al-Rashed, A.A.; Afrand, M. Numerical investigation of forced convection heat transfer and flow irreversibility in a novel heatsink with helical microchannels working with biologically synthesized water-silver nano-fluid. Int. Commun. Heat Mass Transf. 2019, 108, 104324. [CrossRef]

18. Liu, W.; Al-Rashed, A.A.; AlSagri, A.S.; Mahmoudi, B.; Afrand, M.; Afrand, M. Laminar forced convection performance of non-Newtonian water- $\mathrm{CNT} / \mathrm{Fe}_{3} \mathrm{O}_{4}$ nano-fluid inside a minichannel hairpin heat exchanger: Effect of inlet temperature. Powder Technol. 2019, 354, 247-258. [CrossRef]

19. Yang, L.; Ji, W.; Mao, M.; Huang, J.-N. An updated review on the properties, fabrication and application of hybrid-nanofluids along with their environmental effects. J. Clean. Prod. 2020, 257, 120408. [CrossRef]

20. Geng, Y.; Al-Rashed, A.A.A.A.; Mahmoudi, B.; AlSagri, A.S.; Shahsavar, A.; Sardari, P.T. Characterization of the nanoparticles, the stability analysis and the evaluation of a new hybrid nano-oil thermal conductivity. J. Therm. Anal. Calorim. 2019, 139, 1553-1564. [CrossRef]

21. Wu, H.; Al-Rashed, A.A.; Barzinjy, A.A.; Shahsavar, A.; Karimi, A.; Talebizadehsardari, P. Curve-fitting on experimental thermal conductivity of motor oil under influence of hybrid nano additives containing multi-walled carbon nanotubes and zinc oxide. Phys. A Stat. Mech. Appl. 2019, 535, 122128. [CrossRef]

22. Shahsavar, A.; Talebizadeh, P.; Toghraie, D. Free convection heat transfer and entropy generation analysis of water- $\mathrm{Fe}_{3} \mathrm{O}_{4} / \mathrm{CNT}$ hybrid nanofluid in a concentric annulus. Int. J. Numer. Methods Heat Fluid Flow 2019, 29, 915-934. [CrossRef] 
23. Shahsavar, A.; Godini, A.; Sardari, P.T.; Toghraie, D.; Salehipour, H. Impact of variable fluid properties on forced convection of $\mathrm{Fe}_{3} \mathrm{O}_{4} / \mathrm{CNT} /$ water hybrid nanofluid in a double-pipe mini-channel heat exchanger. J. Therm. Anal. Calorim. 2019, 137, 1031-1043. [CrossRef]

24. Salman, S.; Talib, A.R.A.; Saadon, S.; Sultan, M.T.H. Hybrid nanofluid flow and heat transfer over backward and forward steps: A review. Powder Technol. 2020, 363, 448-472. [CrossRef]

25. Li, L.; Tang, Z.; Li, H.; Gao, W.; Yue, Z.; Xie, G. Convective heat transfer characteristics of twin-web turbine disk with pin fins in the inner cavity. Int. J. Therm. Sci. 2020, 152, 106303. [CrossRef]

26. Chorin, P.; Moreau, F.; Saury, D. Heat transfer modification of a natural convection flow in a differentially heated cavity by means of a localized obstacle. Int. J. Therm. Sci. 2020, 151, 106279. [CrossRef]

27. Giwa, S.; Sharifpur, M.; Meyer, J. Effects of uniform magnetic induction on heat transfer performance of aqueous hybrid ferrofluid in a rectangular cavity. Appl. Therm. Eng. 2020, 170, 115004. [CrossRef]

28. El Mansouri, A.; Hasnaoui, M.; Amahmid, A.; Alouah, M. Numerical analysis of conjugate convectionconduction heat transfer in an air-filled cavity with a rhombus conducting block subjected to subdivision: Cooperating and opposing roles. Int. J. Heat Mass Transf. 2020, 150, 119375. [CrossRef]

29. Thiers, N.; Gers, R.; Skurtys, O. Heat transfer enhancement by localised time varying thermal perturbations at hot and cold walls in a rectangular differentially heated cavity. Int. J. Therm. Sci. 2020, 151, 106245. [CrossRef]

30. Ataei-Dadavi, I.; Rounaghi, N.; Chakkingal, M.; Kenjeres, S.; Kleijn, C.R.; Tummers, M.J. An experimental study of flow and heat transfer in a differentially side heated cavity filled with coarse porous media. Int. J. Heat Mass Transf. 2019, 143, 118591. [CrossRef]

31. Farsani, R.Y.; Mahmoudi, A.; Jahangiri, M. How a conductive baffle improves melting characteristic and heat transfer in a rectangular cavity filled with gallium. Therm. Sci. Eng. Prog. 2020, 16, 100453. [CrossRef]

32. Vishnu, A.; Aravind, G.; Deepu, M.; Sadanandan, R. Effect of heat transfer on an angled cavity placed in supersonic flow. Int. J. Heat Mass Transf. 2019, 141, 1140-1151. [CrossRef]

33. Sadaghiani, A.K.; Altay, R.; Noh, H.; Kwak, H.J.; Şendur, K.; Mısırlığlu, B.; Park, H.S.; Koşar, A. Effects of bubble coalescence on pool boiling heat transfer and critical heat flux-A parametric study based on artificial cavity geometry and surface wettability. Int. J. Heat Mass Transf. 2020, 147, 118952. [CrossRef]

34. Pan, M.; Wang, H.; Zhong, Y.; Hu, M.; Zhou, X.; Dong, G.; Huang, P. Experimental investigation of the heat transfer performance of microchannel heat exchangers with fan-shaped cavities. Int. J. Heat Mass Transf. 2019, 134, 1199-1208. [CrossRef]

35. Balotaki, H.K.; Havaasi, H.; KhakRah, H.; Hooshmand, P.; Ross, D. WITHDRAWN: Modelling of free convection heat transfer in a triangular cavity equipped using double distribution functions (DDF) lattice Boltzmann method (LBM). Therm. Sci. Eng. Prog. 2020, 100495. [CrossRef]

36. Liu, Y.; Huang, H. Effect of three modes of linear thermal forcing on convective flow and heat transfer in rectangular cavities. Int. J. Heat Mass Transf. 2020, 147, 118951. [CrossRef]

37. Seo, Y.M.; Luo, K.; Ha, M.Y.; Park, Y.G. Direct numerical simulation and artificial neural network modeling of heat transfer characteristics on natural convection with a sinusoidal cylinder in a long rectangular enclosure. Int. J. Heat Mass Transf. 2020, 152, 119564. [CrossRef]

38. Razzaghpanah, Z.; Sarunac, N. Natural convection heat transfer from a bundle of in-line heated circular cylinders immersed in molten solar salt. Int. J. Heat Mass Transf. 2020, 148, 119032. [CrossRef]

39. Krakov, M.; Nikiforov, I. Influence of the shape of the inner boundary on thermomagnetic convection in the annulus between horizontal cylinders: Heat transfer enhancement. Int. J. Therm. Sci. 2020, 153, 106374. [CrossRef]

40. Pawar, A.P.; Sarkar, S.; Saha, S.K. Forced convective flow and heat transfer past an unconfined blunt headed cylinder at different angles of incidence. Appl. Math. Model. 2020, 82, 888-915. [CrossRef]

41. Alam, M.; Abdelhamid, T.; Sohankar, A. Effect of cylinder corner radius and attack angle on heat transfer and flow topology. Int. J. Mech. Sci. 2020, 175, 105566. [CrossRef]

42. Vyas, A.; Mishra, B.; Srivastava, A. Investigation of the effect of blockage ratio on flow and heat transfer in the wake region of a cylinder embedded in a channel using whole field dynamic measurements. Int. J. Therm. Sci. 2020, 153, 106322. [CrossRef]

43. Hadžiabdić, M.; Palkin, E.; Mullyadzhanov, R.; Hanjalić, K. Heat transfer in flow around a rotary oscillating cylinder at a high subcritical Reynolds number: A computational study. Int. J. Heat Fluid Flow 2019, 79, 108441. [CrossRef] 
44. Aladdin, N.A.L.; Bachok, N.; Pop, I. $\mathrm{Cu}-\mathrm{Al}_{2} \mathrm{O}_{3}$ /water hybrid nanofluid flow over a permeable moving surface in presence of hydromagnetic and suction effects. Alex. Eng. J. 2020, 59, 657-666. [CrossRef]

45. Tseng, Y.; Ferng, Y.; Lin, C. Investigating flow and heat transfer characteristics in a fuel bundle with split-vane pair grids by CFD methodology. Ann. Nucl. Energy 2014, 64, 93-99. [CrossRef]

46. Chowdhury, D.; Neogi, S. Thermal performance evaluation of traditional walls and roof used in tropical climate using guarded hot box. Constr. Build. Mater. 2019, 218, 73-89. [CrossRef]

47. Jamil, B.; Akhtar, N. Effect of specific height on the performance of a single slope solar still: An experimental study. Desalination 2017, 414, 73-88. [CrossRef]

48. Qin, H.; Wang, C.; Zhang, D.; Tian, W.; Su, G.; Qiu, S. Parametric investigation of radiation heat transfer and evaporation characteristics of a liquid droplet radiator. Aerosp. Sci. Technol. 2020, 106, 106214. [CrossRef]

49. Kan, K.; Zheng, Y.; Chen, H.; Zhou, D.; Dai, J.; Binama, M.; Yu, A. Numerical simulation of transient flow in a shaft extension tubular pump unit during runaway process caused by power failure. Renew. Energy 2020, 154, 1153-1164. [CrossRef]

50. Naung, S.W.; Rahmati, M.; Farokhi, H. Direct Numerical Simulation of Interaction between Transient Flow and Blade Structure in a Modern Low-Pressure Turbine. Int. J. Mech. Sci. 2020, 106104. [CrossRef]

51. Kan, K.; Chen, H.; Zheng, Y.; Zhou, D.; Binama, M.; Dai, J. Transient characteristics during power-off process in a shaft extension tubular pump by using a suitable numerical model. Renew. Energy 2021, 164, 109-121. [CrossRef]

52. Abdelhafiz, M.M.; Hegele, L.A.; Oppelt, J.F. Numerical transient and steady state analytical modeling of the wellbore temperature during drilling fluid circulation. J. Pet. Sci. Eng. 2020, 186, 106775. [CrossRef]

53. Ma, Y.; Mohebbi, R.; Rashidi, M.; Yang, Z. MHD convective heat transfer of Ag-MgO/water hybrid nanofluid in a channel with active heaters and coolers. Int. J. Heat Mass Transf. 2019, 137, 714-726. [CrossRef]

54. Kuehn, T.; Goldstein, R. Numerical solution to the Navier-Stokes equations for laminar natural convection about a horizontal isothermal circular cylinder. Int. J. Heat Mass Transf. 1980, 23, 971-979. [CrossRef]

55. Liu, D.; Yu, L. Experimental investigation of single-phase convective heat transfer of nanofluids in a minichannel. In Proceedings of the 14th International Heat Transfer Conference, IHTC14, Washington, DC, USA, 8-13 August 2010.

Publisher's Note: MDPI stays neutral with regard to jurisdictional claims in published maps and institutional affiliations.

(C) 2020 by the authors. Licensee MDPI, Basel, Switzerland. This article is an open access article distributed under the terms and conditions of the Creative Commons Attribution (CC BY) license (http://creativecommons.org/licenses/by/4.0/). 